\title{
The Anticyclone: A Device for Nonimpact Particle Separation
}

\author{
J. R. Torczynski, D. J. Rader
}

\section{Prepared by}

Sandia National Laboratories

Albuquerque, New Mexico 87185 and Livermore, California 94550

for the United States Department of Energy

under Contract DE-AC04-94AL85000

Approved for public release; distritribution is unlimited.

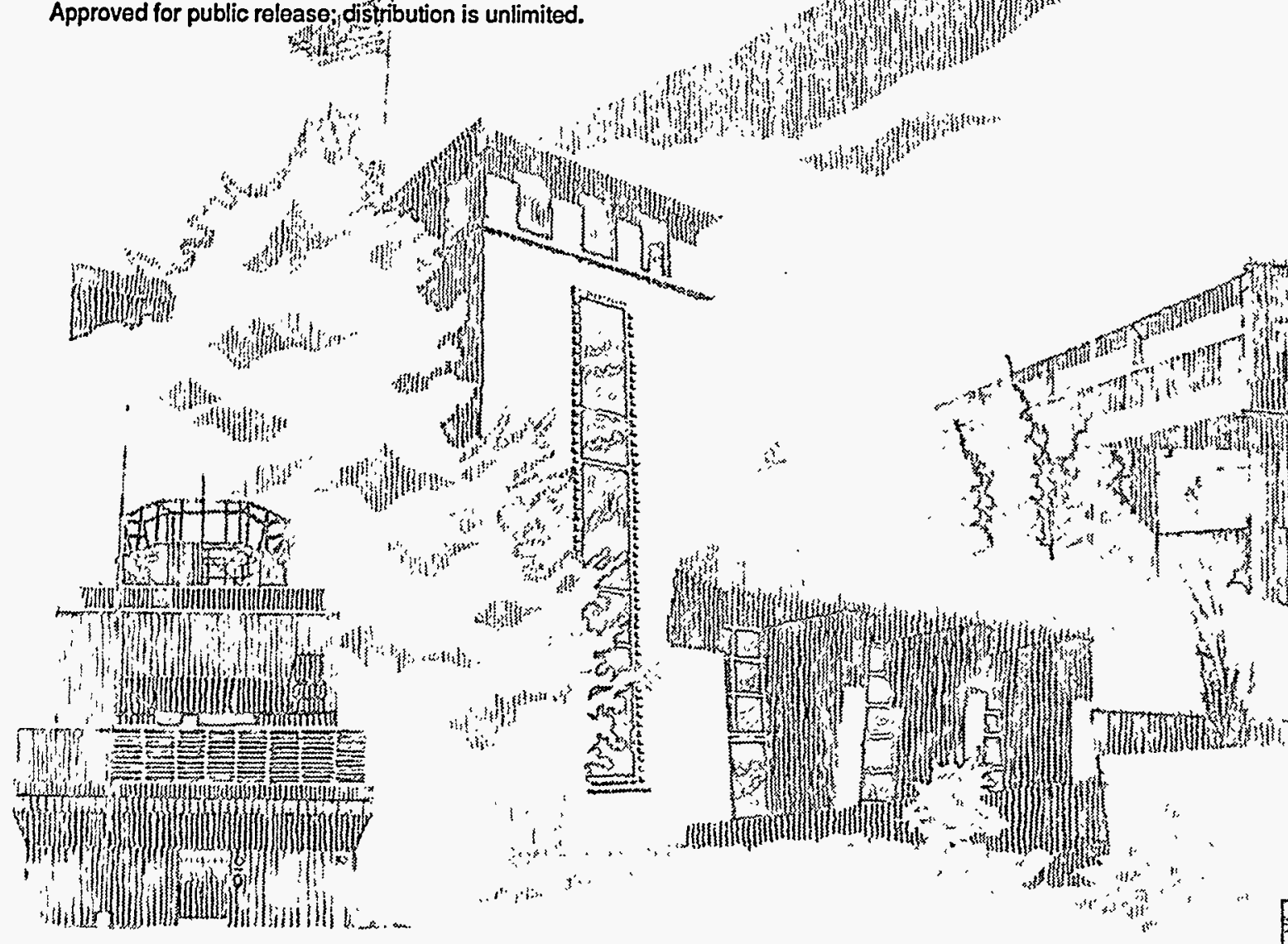


Issued by Sandia National Laboratories, operated for the United States Department of Energy by Sandia Corporation.

NOTICE: This report was prepared as an account of work sponsored by an agency of the United States Government. Neither the United States Government nor any agency thereof, nor any of their employees, nor any of their contractors, subcontractors, or their employees, makes any warranty, express or implied, or assumes any legal liability or responsibility for the accuracy, completeness, or usefulness of any information, apparatus, product, or process disclosed, or represents that its use would not infringe privately owned rights. Reference herein to any specific commercial product, process, or service by trade name, trademark, manufacturer, or otherwise, does not necessarily constitute or imply its endorsement, recommendation, or favoring by the United States Government, any agency thereof or any of their contractors or subcontractors. The views and opinions expressed herein do not necessarily state or reflect those of the United States Government, any agency thereof or any of their contractors.

Printed in the United States of America. This report has been reproduced directly from the best available copy.

Available to DOE and DOE contractors from

Office of Scientific and Technical Information

PO Box 62

Oak Ridge, TN 37831

Prices available from (615) 576-8401, FTS 626-8401

Available to the public from

National Technical Information Service

US Department of Commerce

5285 Port Royal Rd

Springfield, VA 22161

NTIS price codes

Printed copy: A03

Microfiche copy: A01 
SAND96-0728

Distribution

Unlimited Release

Category UC-406

Printed March 1996

\title{
The Anticyclone: A Device for Nonimpact Particle Separation
}

\author{
J. R. Torczynski, D. J. Rader \\ Engineering Sciences Center \\ Sandia National Laboratories \\ Albuquerque, New Mexico 87185
}

\begin{abstract}
It is often desirable to separate particles from a particle-laden fluid stream. This is typically accomplished by passing the stream through a filter, an impactor, or a cyclone. In each of these devices, particles encounter obstacles in the flow path (i.e. filter material, the impaction surface, the cyclone side wall). However, in some applications, it is desirable to prevent particles from impinging on solid surfaces. For example, particle interaction with a solid surface may contaminate the surface, modify the particles via mechanical or chemical processes, or adversely affect the surface via material modification or heat transfer. In such situations, it is still possible to separate particles from the particle-laden flow stream by transferring them to another adjacent flow stream. This transfer of particles from one flow stream to another is termed nonimpact particle separation. One type of device that separates particles from a flow stream by nonimpact particle separation is the anticyclone. In contradistinction to a cyclone, the particle-laden flow is deflected from its original direction by a wall that curves away from the original flow direction, rather than into it. The computational fluid dynamics code FIDAP (Fluid Dynamics International) is used to perform two-dimensional fluid-flow and particle-motion calculations for a representative device geometry. These calculations indicate that the anticyclone geometry examined accomplishes nonimpact particle separation, as expected. Flow patterns and overall particle-separation characteristics are found to be fairly insensitive to Reynolds number for values above 100 regardless of whether the flow is laminar or turbulent. An approximate analytical relation describing anticyclone nonimpact particle separation is developed and validated by comparison to the numerical simulations. The additional information required to design useful devices employing nonimpact particle separation is outlined.
\end{abstract}




\section{Acknowledgment}

The authors gratefully acknowledge interactions with John E. Brockmann and Fred Gelbard of Sandia National Laboratories. 


\section{Contents}

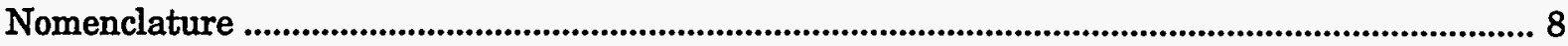

1. Nonimpact Particle Separation and the Anticyclone ............................................................ 9

2. FIDAP Fluid-Flow and Particle-Motion Simulations ............................................................ 12

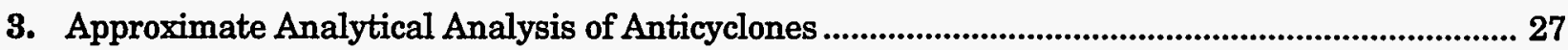

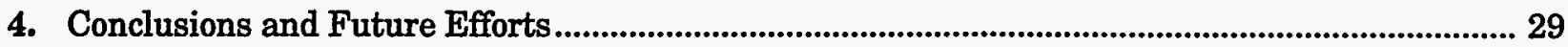

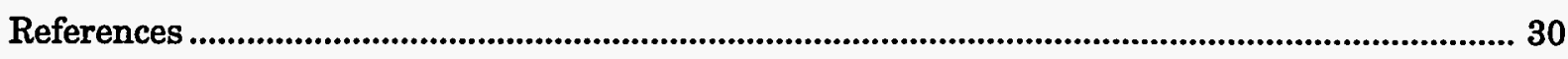

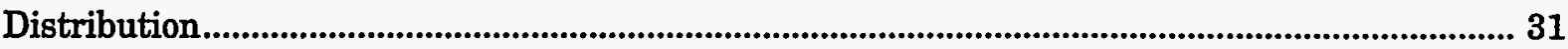




\section{Figures}

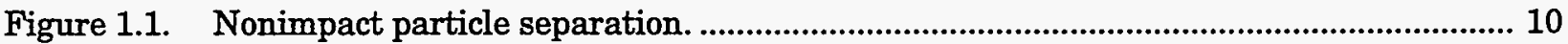

Figure 1.2. Schematic diagram of an anticyclone.................................................................... 11

Figure 2.1. Streamlines (top) and speed contours (bottom) for $R e=10^{1}$ (laminar)....................... 15

Figure 2.2. Streamlines (top) and speed contours (bottom) for $R e=10^{2}$ (laminar)....................... 16

Figure 2.3. Streamlines (top) and speed contours (bottom) for $R e=10^{3}$ (laminar)....................... 17

Figure 2.4. Streamlines (top) and speed contours (bottom) for $R e=10^{4}$ (laminar)........................ 18

Figure 2.5. Streamlines (top) and speed contours (bottom) for $R e=10^{3}$ (turbulent). ................... 19

Figure 2.6. Streamlines (top) and speed contours (bottom) for $R e=10^{4}$ (turbulent).................... 20

Figure 2.7. Streamlines (top) and speed contours (bottom) for $R e=10^{5}$ (turbulent). .................... 21

Figure 2.8. Streamlines (top) and speed contours (bottom) for $R e=10^{6}$ (turbulent). ..................... 22

Figure 2.9. Streamlines (top) and speed contours (bottom) for $R e=10^{7}$ (turbulent). .................... 23

Figure 2.10. Particle motion for $R e=10^{6}$ (turbulent): $D_{p} / 2 H=1.0 \times 10^{-4}, \rho_{p} / \rho=1.2 \times 10^{4} \ldots \ldots \ldots \ldots . . .24$

Figure 2.11. Particle motion for $R e=10^{6}$ (turbulent): $D_{p} / 2 H=1.0 \times 10^{-4}, \rho_{p} / \rho=0.6 \times 10^{4} \ldots \ldots \ldots \ldots .24$

Figure 2.12. Particle motion for $R e=10^{6}$ (turbulent): $D_{p} / 2 H=1.0 \times 10^{-4}, \rho_{p} / \rho=0.3 \times 10^{4} \ldots \ldots \ldots . . . .25$

Figure 2.13. Particle motion for $R e=10^{6}$ (turbulent): $D_{p} / 2 H=0.5 \times 10^{-4}, \rho_{p} / \rho=1.2 \times 10^{4} \ldots \ldots \ldots \ldots . . .25$

Figure 2.14. Particle motion for $R e=10^{6}$ (turbulent): $D_{p} / 2 H=0.5 \times 10^{-4}, \rho_{p} / \rho=0.6 \times 10^{4} \ldots \ldots \ldots \ldots . .26$

Figure 2.15. Particle motion for $R e=10^{6}$ (turbulent): $D_{p} / 2 H=0.5 \times 10^{-4}, \rho_{p} / \rho=0.3 \times 10^{4} \ldots \ldots \ldots \ldots .26$ 


\section{Tables}

Table 2.1. Anticyclone physical and geometric parameters. .................................................. 12

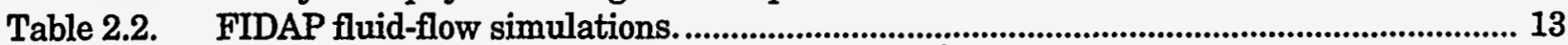

Table 2.3. FIDAP particle-motion simulations for $R e=10^{6}$ (turbulent). ....................................... 14

Table 3.1. Comparison of analytical and simulation results for the exit angle. ............................28 


\section{Nomenclature}

$\tilde{c}_{D} \quad$ normalized drag coefficient, 1 for $R e_{p}=0$

$D_{p} \quad$ particle diameter

$\hat{e} \quad$ unit normal vector

$\vec{g} \quad$ gravitational acceleration (vector)

$H \quad$ inlet width

$L \quad$ width in third dimension, normal to plane of calculation

$m \quad$ particle trajectory parameter

$m_{E} \quad$ particle trajectory parameter for particles with $R_{0}=R_{1}$

$R_{0} \quad$ particle radial position at inlet

$R_{1} \quad$ radius of curvature at inner edge of inlet

$R_{2} \quad$ radius of curvature at outer edge of inlet, $R_{2}=R_{1}+H$

Re Reynolds number for fluid, $R e=\rho U(2 H) / \mu$

$R e_{p} \quad$ Reynolds number for particle, $R e_{p}=\rho D_{p}\left|\vec{u}_{p}-\vec{u}\right| / \mu$

$r$

$\dot{r} \quad$ time derivative of $r$

$\ddot{r} \quad$ time derivative of $\dot{r}$

St $\quad$ Stokes number, $S t=\rho_{p} D_{p}^{2} U / 18 \mu R_{1}$

particle trajectory quantity, $s=r^{-1}(d r / d \theta)$

$t \quad$ time

$U$ average fluid velocity in inlet

$\vec{u} \quad$ fluid velocity (vector)

$\vec{u}_{p} \quad$ particle velocity (vector)

$W \quad$ outlet width

$\vec{x} \quad$ fluid position (vector)

$\vec{x}_{p} \quad$ particle position (vector)

$\mu \quad$ fluid absolute viscosity

$\rho \quad$ fluid mass density

$\rho_{p} \quad$ particle mass density

$\theta$ angular position with respect to the center of curvature, 0 at the inlet

$\dot{\theta} \quad$ time derivative of $\theta$

$\ddot{\theta} \quad$ time derivative of $\dot{\theta}$

$\theta_{E} \quad$ angular position at which all particles have exited the particle-laden flow 


\section{Nonimpact Particle Separation and the Anticyclone}

Many systems for separating particles from a fluid stream rely on one of three particle-separation technologies: filters, impactors, and cyclones. Filters separate particles from a fluid by trapping them on or in a sheet of porous material, which is often composed of closely packed fibers or granular material. As the particle-laden fluid passes through the filter material, particles become lodged in narrow gaps in the material or stick directly to it. Impactors separate particles from a fluid by depositing them onto a wall. A jet of particle-laden fluid is directed toward a wall at normal incidence. Although the fluid is turned by the wall, the drag force on the particles is insufficient to overcome particle inertia and thereby prevent the particles from impacting onto the wall. Cyclones separate particles from a fluid through centrifugal action produced with a swirling flow. The particle-laden fluid is injected tangentially into a barrel-shaped enclosure, producing a swirling flow. Centrifugal effects cause particles to migrate outward to the side wall, along which they travel until they are subsequently collected.

Although these three technologies appear quite different at first glance, they actually share two features in common. First, they all involve placing obstacles in the flow path. Both impactors and cyclones employ a wall to turn the flow. For impactors, the wall is perpendicular to the flow, whereas for cyclones, the wall curves gradually into the flow. A filter is a porous wall generally oriented normally to the flow, or, equivalently, at the microscale, a filter is a collection of fiber-like or granular obstacles placed in the flow path. Second, particle separation in all of these devices is accomplished principally by the inability of the particles to "make the turn" and follow the flow: the particles" inertia causes them to impinge upon the obstacle that deflects the flow (diffusive transport can also occur). For impactors and filters, particles actually become attached to the flow obstacles, whereas for cyclones, the particles slide or roll along the side wall until exiting the swirling region.

Placing a wall in the flow path can be undesirable for several reasons. First, the particles may have physical, chemical, or biological properties (e.g. radioactivity) that make it undesirable to contaminate a surface by depositing particles on it. Second, the impact of particles on solid surfaces may have undesirable effects on particle properties via fragmentation, agglomeration, or chemical reactions and on surface properties and structural integrity via abrasion, heat transfer, or chemical reactions. Third, particles deposited onto a surface can be easily reentrained into the main flow, particularly in the presence of flow transients or mechanical vibrations. Fourth, pressure drops can be large for impact-based technologies, which limits processing and transport rates or increases device size to achieve a prescribed processing rate.

From the above discussion, it is clear that separating particles from a flow stream without placing an obstacle in the flow path which both deflects the flow and collects the particles is desirable at times. This can be accomplished by "nonimpact particle separation" (see Figure 1.1), which denotes taking particles initially distributed throughout one flow stream and transporting them to an adjacent flow stream. The aerodynamic lens and the virtual impactor are well-known devices employing nonimpact particle separation. A more recently proposed device employing nonimpact particle separation is the anticyclone (see Figure 1.2). In an anticyclone, the main particle-laden flow follows a wall that curves away from the original flow direction rather than curving into the original flow direction, as in a cyclone. Although a wall forms the inner boundary of the main flow, its outer boundary is formed by an adjacent flow, often a confined recirculating flow, into which particles are transferred by centrifugal action. Thus, in the anticyclone, particles are separated from the main flow by crossing a dividing streamline that separates the main flow stream from an adjacent flow stream. Particles can be subsequently separated from the adjacent flow stream or maintained in this stream for further handling, allowing the possibility of multiple anticyclone stages for further concentration of particles. 
The anticyclone nonimpact particle separation approach offers several advantages over more traditional impact-based particle separation approaches under certain circumstances. First, contamination of solid surfaces is minimized since particles do not encounter obstacles. Second, neither particle properties nor surface properties are modified by impact since particles do not impact a solid surface. Third, since the main flow stream does not pass over a particle-coated surface, the potential of reentrainment is minimized. Additionally, particles in the recirculation region are not likely to be reentrained since the streamlines in this region have the same curvature as the streamlines in the main flow, so particles tend to be centrifuged away from the main flow. As will be shown in following sections, the flow pattern is robust, remaining virtually unchanged for Reynolds numbers above 100 regardless of whether the flow is laminar or turbulent, so device operation is largely unaffected by gradual transients. Fourth, the pressure drop is expected to be small since the main flow is turned gradually rather than abruptly and does not experience prolonged swirling. Fifth, the particles remain suspended in the adjacent flow, which facilitates further handling. Sixth, devices can be oriented so that gravity assists particle separation. Seventh, the anticyclone has no moving parts and is geometrically uncomplicated.

Subsequent sections of this report present numerical calculations of fluid flow and particle transport in a representative anticyclone geometry (Chapter 2), an approximate analytical analysis of particleseparation characteristics of anticyclones (Chapter 3), and an assessment of the additional information required to develop useful devices employing nonimpact particle separation (Chapter 4).

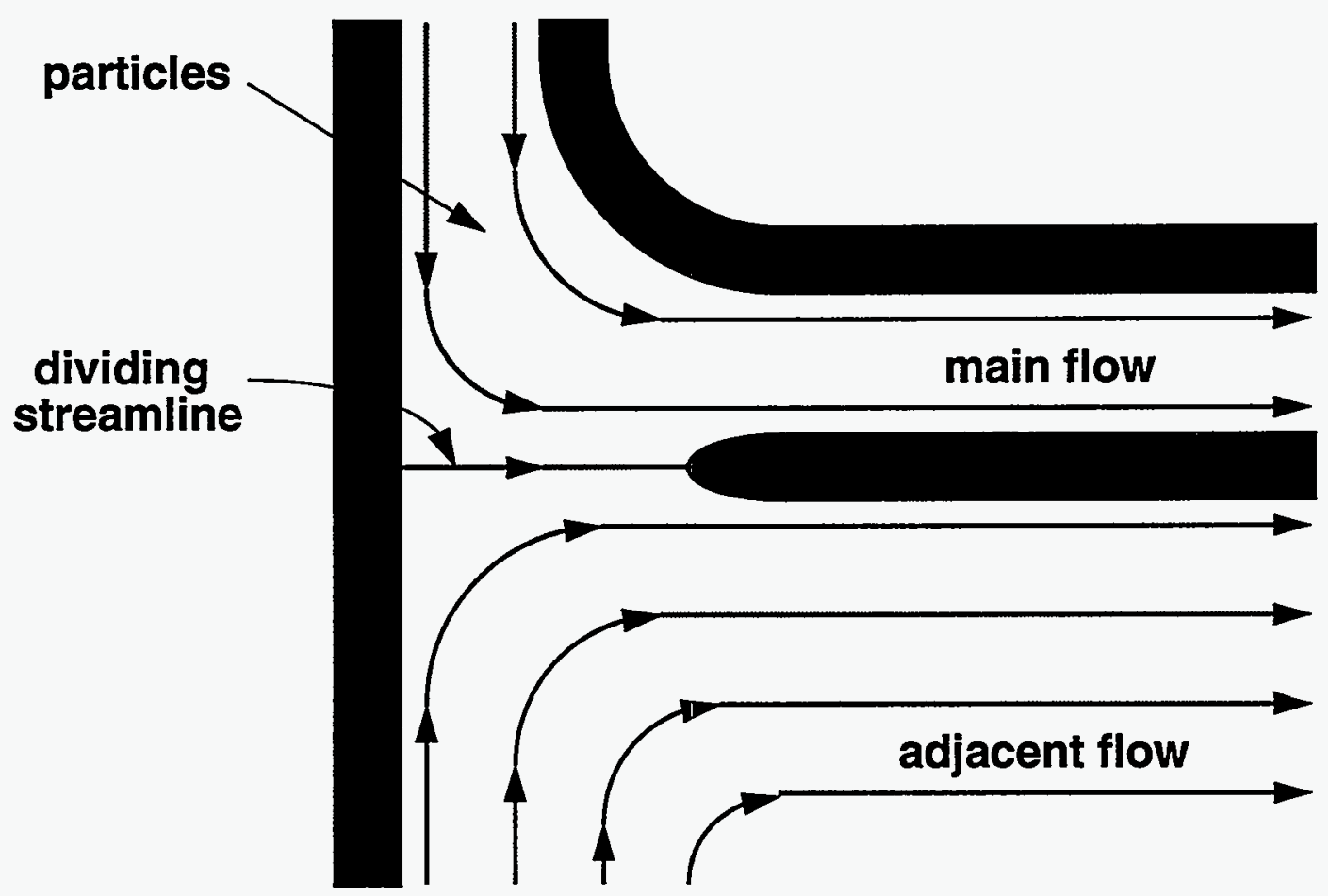

Figure 1.1. Nonimpact particle separation. 


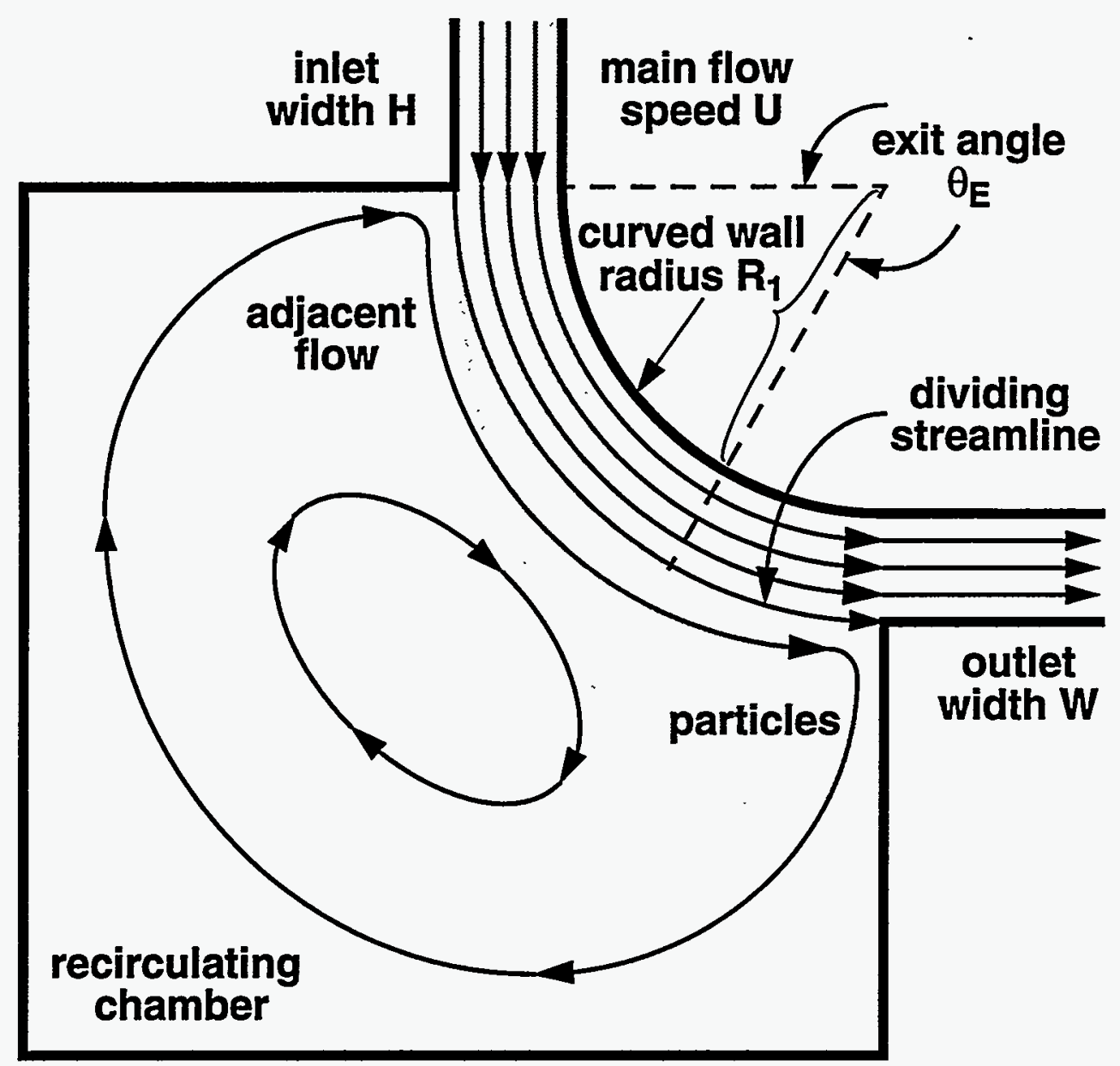

Figure 1.2. Schematic diagram of an anticyclone. 


\section{FIDAP Fluid-Flow and Particle-Motion Simulations}

The computational fluid dynamics code FIDAP (Fluid Dynamics International) [1] has been used to perform fluid-flow and particle-motion simulations for an anticyclone geometry similar to that shown in Figure 1.2. The simulation geometry is not to be understood as an optimum geometry in any sense although careful attention is paid to the specification of certain geometric parameters. In particular, with the (inner) wall radius of curvature and the inlet and outlet widths denoted by $R_{1}, H$, and $W$, respectively, the ratios $H / R_{1}$ and $W / H$ are kept small enough to ensure that the main flow actually follows the curved wall rather than separating, or detaching, from it.

Table 2.1. Anticyclone physical and geometric parameters.

\begin{tabular}{|l|c|c|}
\hline \multicolumn{1}{|c|}{ Quantity } & Symbol & Value \\
\hline \hline Density & $\rho$ & 1 \\
\hline Viscosity & $\mu$ & $1 / R e$ \\
\hline Grav. Accel. & $\vec{g}$ & $(0,0,0)$ \\
\hline Inlet Velocity & $U$ & 1 \\
\hline Wall Radius & $R_{1}$ & 1 \\
\hline Inlet Width & $H$ & 0.5 \\
\hline Outlet Width & $W$ & 0.36 \\
\hline
\end{tabular}

Table 2.1 shows the particular values for geometric and physical parameters used in the simulations. All calculations are performed in nondimensional fashion, where the Reynolds number is defined here to be $R e=\rho U(2 H) / \mu$. The factor of 2 is included because the hydraulic diameter of a long thin slit of length $L$ and width $H$ where $L » H$ is $2 H$. To achieve a specified Reynolds number value, the fluid viscosity is set equal to the appropriate value (cf. Table 2.1).

In the numerical simulations, the flow is assumed to be two-dimensional, steady, incompressible, and isothermal. Thus, the effects of three-dimensionality, flow unsteadiness, compressibility, and thermal convection are neglected in the present simulations. The Reynolds number is selected to range in increasing powers of 10 from a low value of $10^{1}$ to a high value of $10^{7}$. Flows with lower values are laminar whereas flows with higher values are turbulent, so both laminar and turbulent simulations are performed where appropriate. In the turbulent-flow calculations, the standard $k-\varepsilon$ model is employed with the default values of the model coefficients. Since the accuracy of the $k-\varepsilon$ model is uncertain, particularly in complex geometries with recirculating flow, the turbulent simulations should be interpreted as only semi-quantitative at best, rather than as of high quantitative accuracy.

Nine flow simulations are performed with FIDAP. Table 2.2 shows the Reynolds number value and flow type (laminar or turbulent) for these simulations and the figures in which the corresponding streamlines and contour plots of speed are shown. Note that an overlap range of $10^{3} \leq R e \leq 10^{4}$ is included where both laminar and turbulent simulations are performed. This is to account for the fact that both types of flow are possible in this range. 
Table 2.2. FIDAP fluid-flow simulations.

\begin{tabular}{|c|c|c|}
\hline Figure & Reynolds Number $R e$ & Flow Type \\
\hline \hline 2.1 & $10^{1}$ & Laminar \\
\hline 2.2 & $10^{2}$ & Laminar \\
\hline 2.3 & $10^{3}$ & Laminar \\
\hline 2.4 & $10^{4}$ & Laminar \\
\hline 2.5 & $10^{3}$ & Turbulent \\
\hline 2.6 & $10^{4}$ & Turbulent \\
\hline 2.7 & $10^{5}$ & Turbulent \\
\hline 2.8 & $10^{6}$ & Turbulent \\
\hline 2.9 & $10^{7}$ & Turbulent \\
\hline
\end{tabular}

Several observations can be made based on these figures. First, the flow has the basic structure shown in Figure 1.2. The main flow remains attached to the curved wall moving at nearly constant speed along approximately circular streamlines and driving the recirculating flow. This structure is maintained by pressure gradients normal to the wall, which supply the necessary centripetal acceleration, and the recirculating region bounding the main flow acts as a constant-pressure reservoir to turn the main flow. Second, the flow structure is only weakly dependent on Reynolds number for $R e \geq 10^{2}$ regardless of whether the flow is laminar or turbulent. The laminar flows show a progressive thinning of the shear and boundary layers with increasing $R e$, whereas the turbulent flows are virtually identical for $R e \geq 10^{4}$. Thus, the flow structure should be insensitive to modest transients occurring on time scales longer than the time for the main flow to traverse the device.

The fluid-flow simulations previously presented serve as the basis for particle-motion simulations, also performed using FIDAP [1]. The motion of a spherical particle of diameter $D_{p}$ and density $\rho_{p}$ can be described quantitatively by the equations of motion:

$$
\frac{d \vec{x}_{p}}{d t}=\vec{u}_{p}, \frac{d \vec{u}_{p}}{d t}=-\left(\frac{18 \mu}{\rho_{p} D_{p}^{2}}\right) \tilde{c}_{D}\left(\vec{u}_{p}-\vec{u}\right)+\left(1-\rho / \rho_{p}\right) \vec{g} .
$$

Here, $\vec{x}_{p}$ and $\vec{u}_{p}$ are the particle position and velocity, respectively, $\vec{u}$ is the fluid velocity at position $\vec{x}_{p}$ and time $t ; \vec{g}$ is the gravitational acceleration vector, and $\tilde{c}_{D}$ is the normalized drag coefficient. Several assumptions are implicit in this relation [2]. First, the volume fraction occupied by particles is assumed to be small, so particles can be treated as not interacting with each other and as not influencing the particle-laden flow (a dilute flow of isolated particles). In other words, the flow affects the particles, but the particles do not influence the flow or each other. Second, this relation assumes that both virtual-mass effects and Basset-history effects are small. The assumption of negligible virtual-mass effects is appropriate either to high-density particles in a low-density fluid or to quasistatic motion, where forces are almost in balance. The assumption of negligible Basset-history effects is also appropriate to quasi-static motion. Either or both of these assumptions could be relaxed if necessary. Third, turbulence is assumed to affect particle motion only through the mean velocity field: effects of velocity fluctuations are neglected. 
The normalized drag coefficient is a function of the particle Reynolds number $R e_{p}=\rho D_{p}\left|\vec{u}_{p}-\vec{u}\right| / \mu$ and has been normalized to approach unity for small $R e_{p}$. An empirical drag law developed by Turton and Levenspiel [3] for isolated spherical particles with $R e_{p} \leq 10^{5}$ has been incorporated into FIDAP for particle-trajectory calculations:

$$
\tilde{c}_{D}=\tilde{c}_{D}\left[R e_{p}\right]=1+0.173 R e_{p}^{0.657}+\frac{0.0172 R e_{p}}{1+16300 R e_{p}^{-1.09}} .
$$

Representative particle-motion simulations are performed using the simulated flow at $R e=10^{6}$, shown in Figure 2.8. Table 2.3 indicates the figures in which the particle-motion results are shown, the particle diameters and densities used in the simulations (recall that all lengths are normalized by twice the inlet width and that all densities are normalized by the fluid density). Also shown in the table are the corresponding values of the Stokes number, here defined to be $S t=\rho_{p} D_{p}^{2} U / 18 \mu R_{1}$, and the resulting values of the exit angle $\theta_{E}$. Here, the exit angle is defined to be the angular position at which all particles have been transferred from the main particle-laden flow to the adjacent recirculating flow (see Figure 1.2). In all of these simulations, the gravitational acceleration is set equal to 0 so that the flow-induced particle-separation characteristics alone can be observed.

Table 2.3. FIDAP particle-motion simulations for $R e=10^{6}$ (turbulent).

\begin{tabular}{|c|c|c|c|c|}
\hline Figure & Particle Diameter $D_{p} / 2 H$ & Particle Density $\rho_{p} / \rho$ & Stokes Number $S t$ & Exit Angle $\theta_{E}$ \\
\hline \hline 2.10 & $1.0 \times 10^{-4}$ & $1.2 \times 10^{4}$ & 6.67 & $52^{\circ}$ \\
\hline 2.11 & $1.0 \times 10^{-4}$ & $0.6 \times 10^{4}$ & 3.33 & $58^{\circ}$ \\
\hline 2.12 & $1.0 \times 10^{-4}$ & $0.3 \times 10^{4}$ & 1.67 & $71^{\circ}$ \\
\hline 2.13 & $0.5 \times 10^{-4}$ & $1.2 \times 10^{4}$ & 1.67 & $65^{\circ}$ \\
\hline 2.14 & $0.5 \times 10^{-4}$ & $0.6 \times 10^{4}$ & 0.83 & $87^{\circ}$ \\
\hline 2.15 & $0.5 \times 10^{-4}$ & $0.3 \times 10^{4}$ & 0.42 & not achieved \\
\hline
\end{tabular}

Several observations can be made based on these figures. As expected, the best particle separation (smallest $\theta_{E}$ ) is achieved for the particles with the largest diameter and density (shown in Figure 2.10). These particles are not greatly affected by the flow: they leave the particle-laden fluid and propagate down into the recirculating region along fairly straight trajectories (the downward vertical motion is caused by inertia, not gravity). Similarly, the worst particle separation (largest $\theta_{E}$ ) is achieved for the particles with the smallest diameter and density (shown in Figure 2.15). In this case, only about $60-70 \%$ of the particles are separated from the particle-laden flow into the recirculating region; nevertheless, all of the remaining particles impact the side wall. 

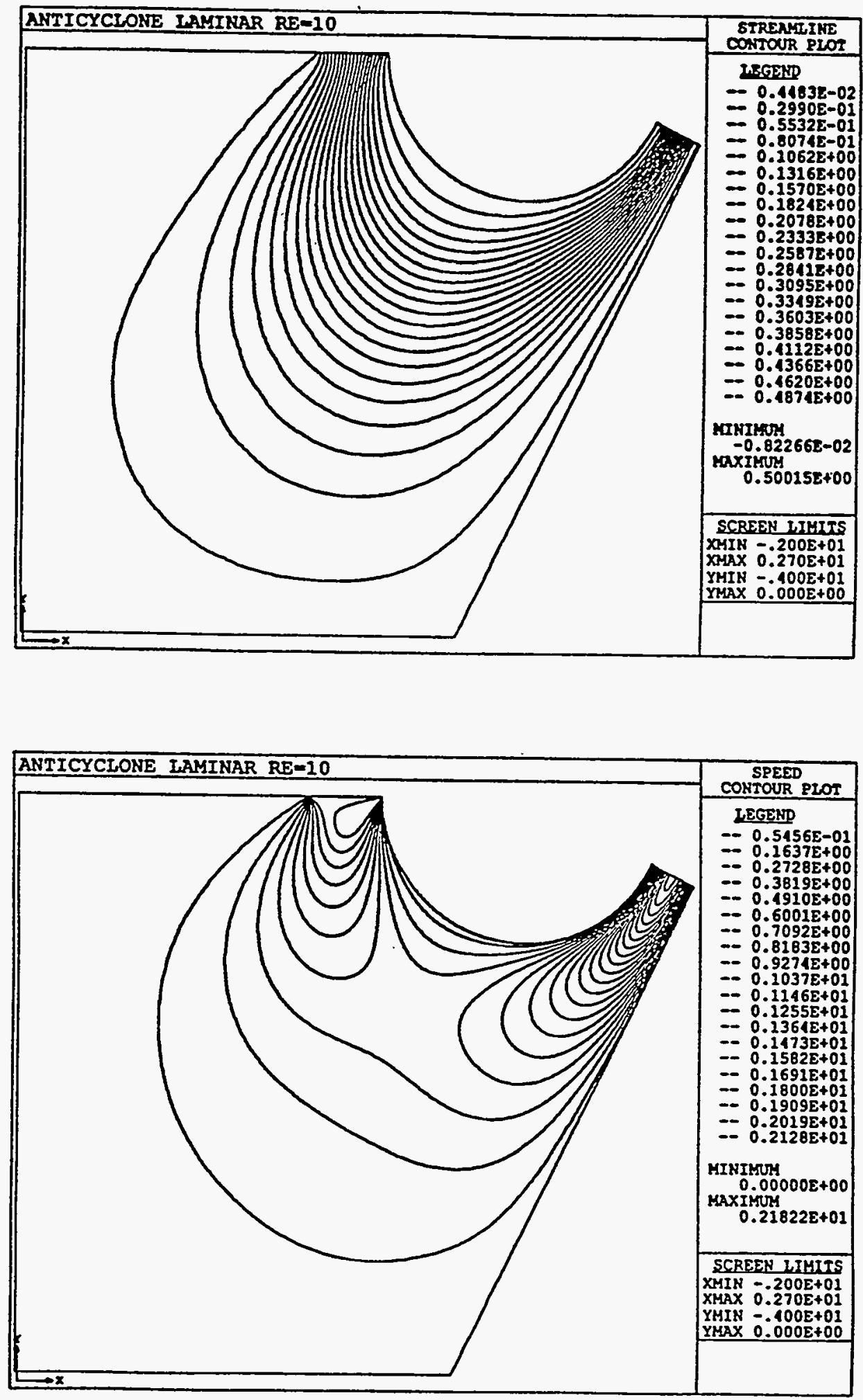

Figure 2.1. Streamlines (top) and speed contours (bottom) for $R e=10^{1}$ (laminar). 

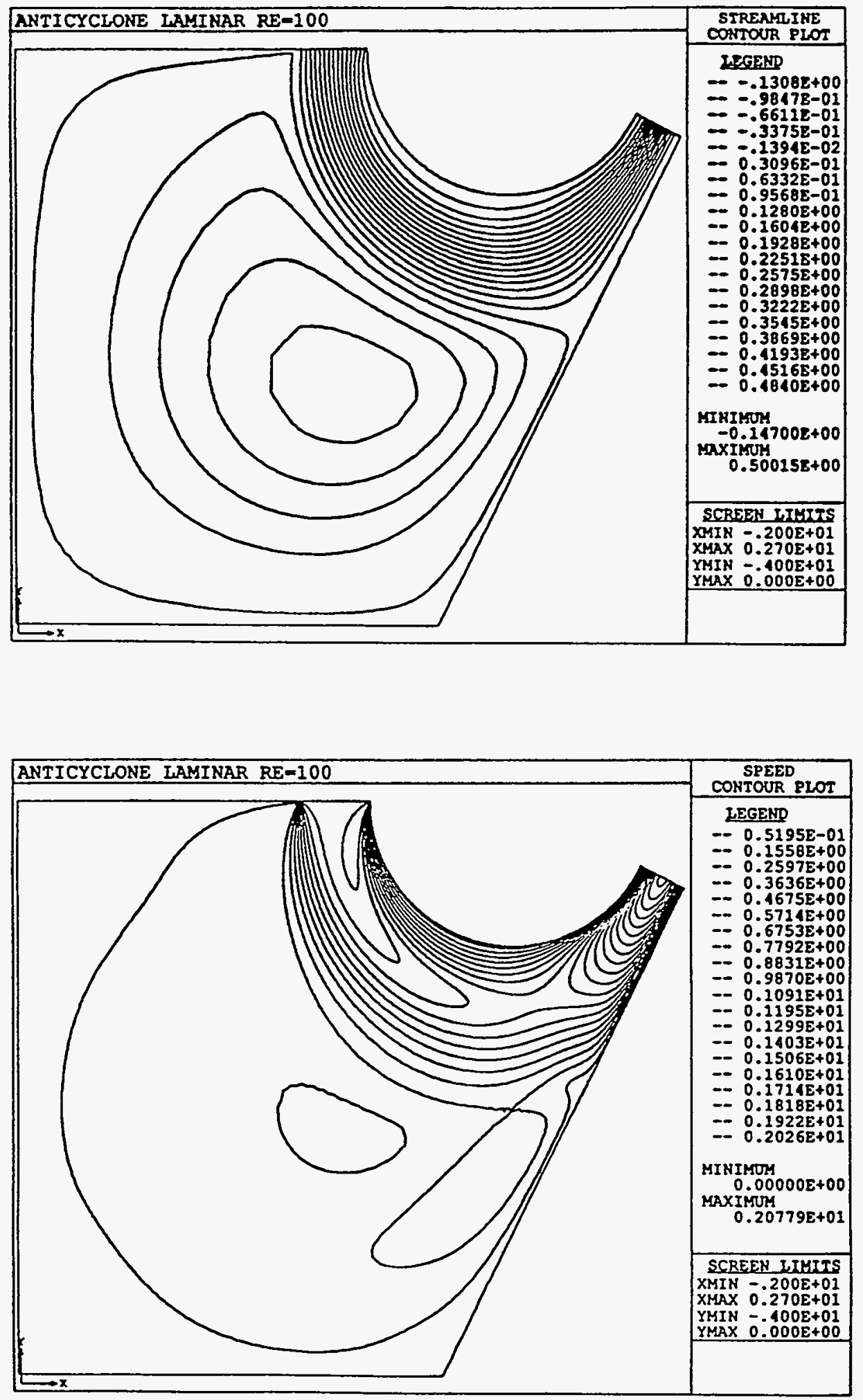

Figure 2.2. Streamlines (top) and speed contours (bottom) for $R e=10^{2}$ (laminar). 

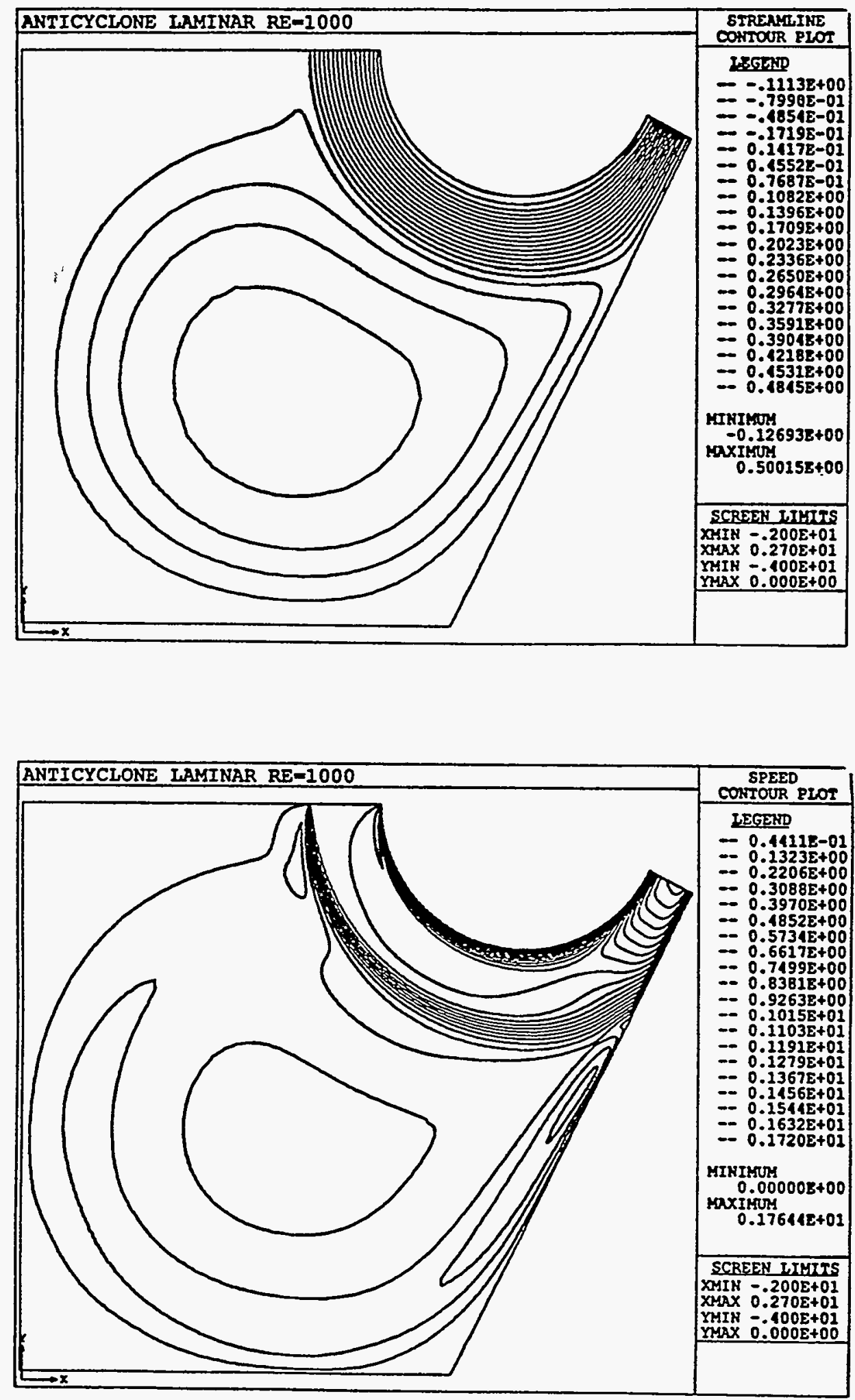

Figure 2.3. Streamlines (top) and speed contours (bottom) for $R e=10^{3}$ (laminar). 

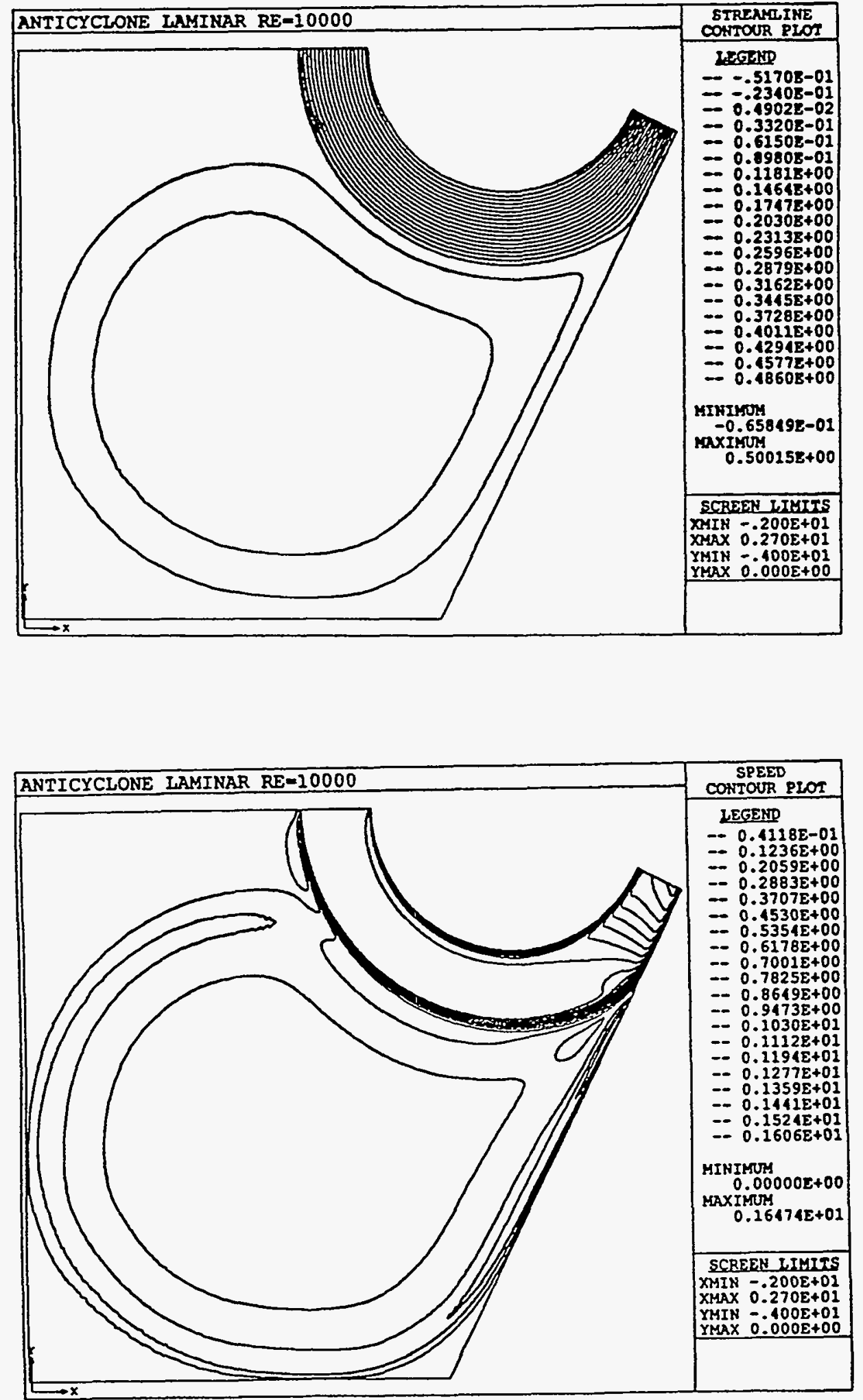

Figure 2.4. Streamlines (top) and speed contours (bottom) for $R e=10^{4}$ (laminar). 

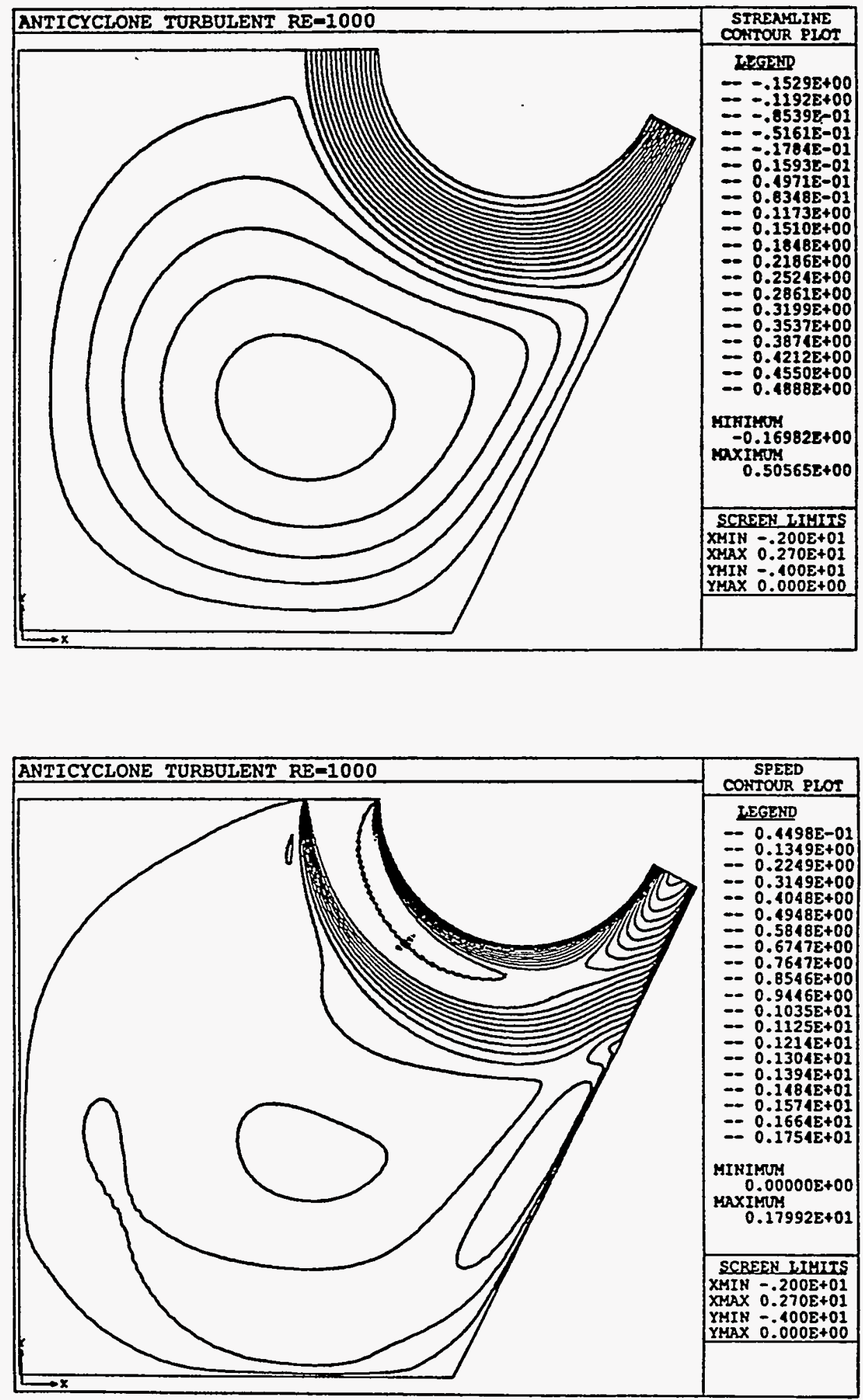

Figure 2.5. Streamlines (top) and speed contours (bottom) for $R e=10^{3}$ (turbulent). 

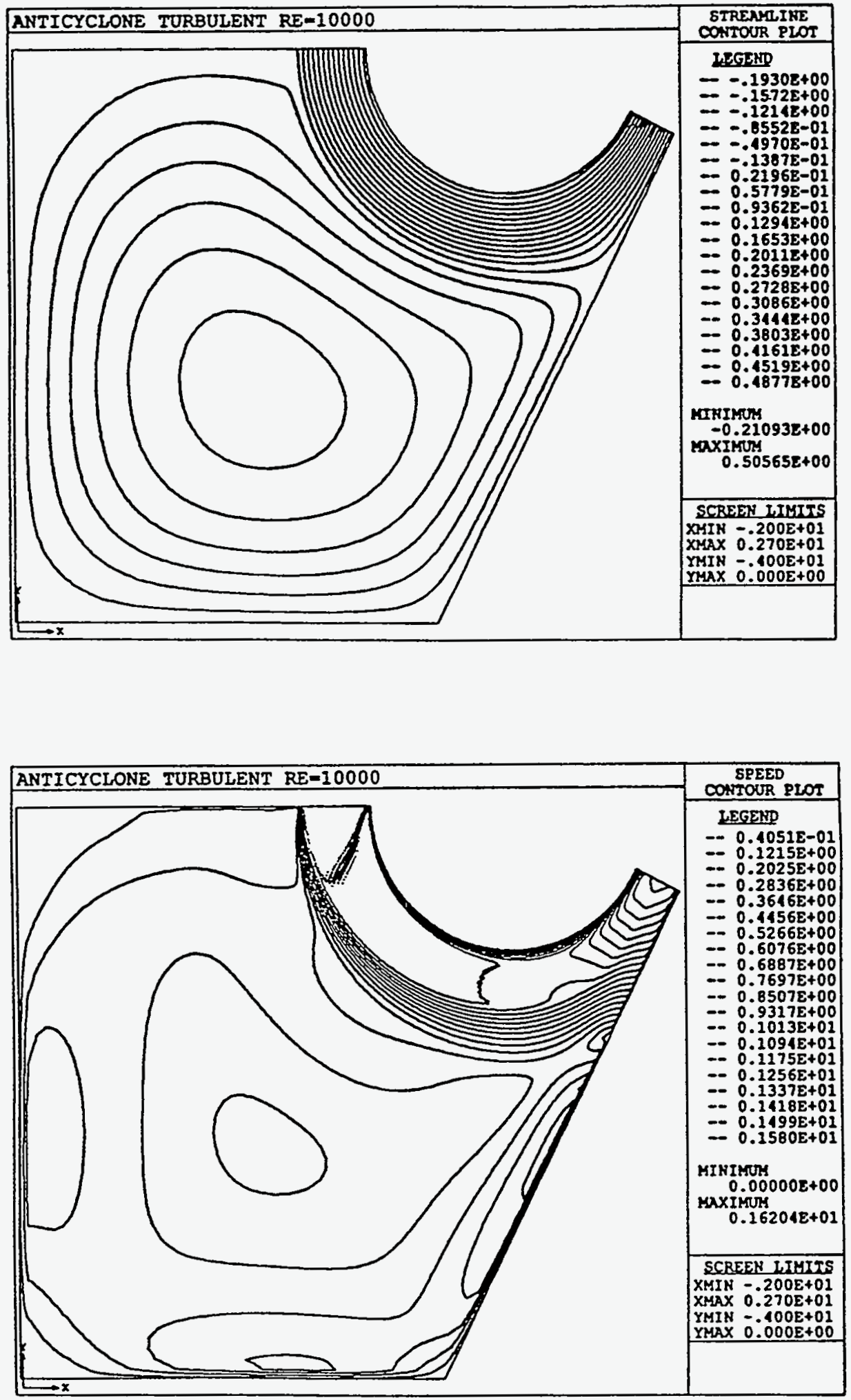

Figure 2.6. Streamlines (top) and speed contours (bottom) for $R e=10^{4}$ (turbulent). 

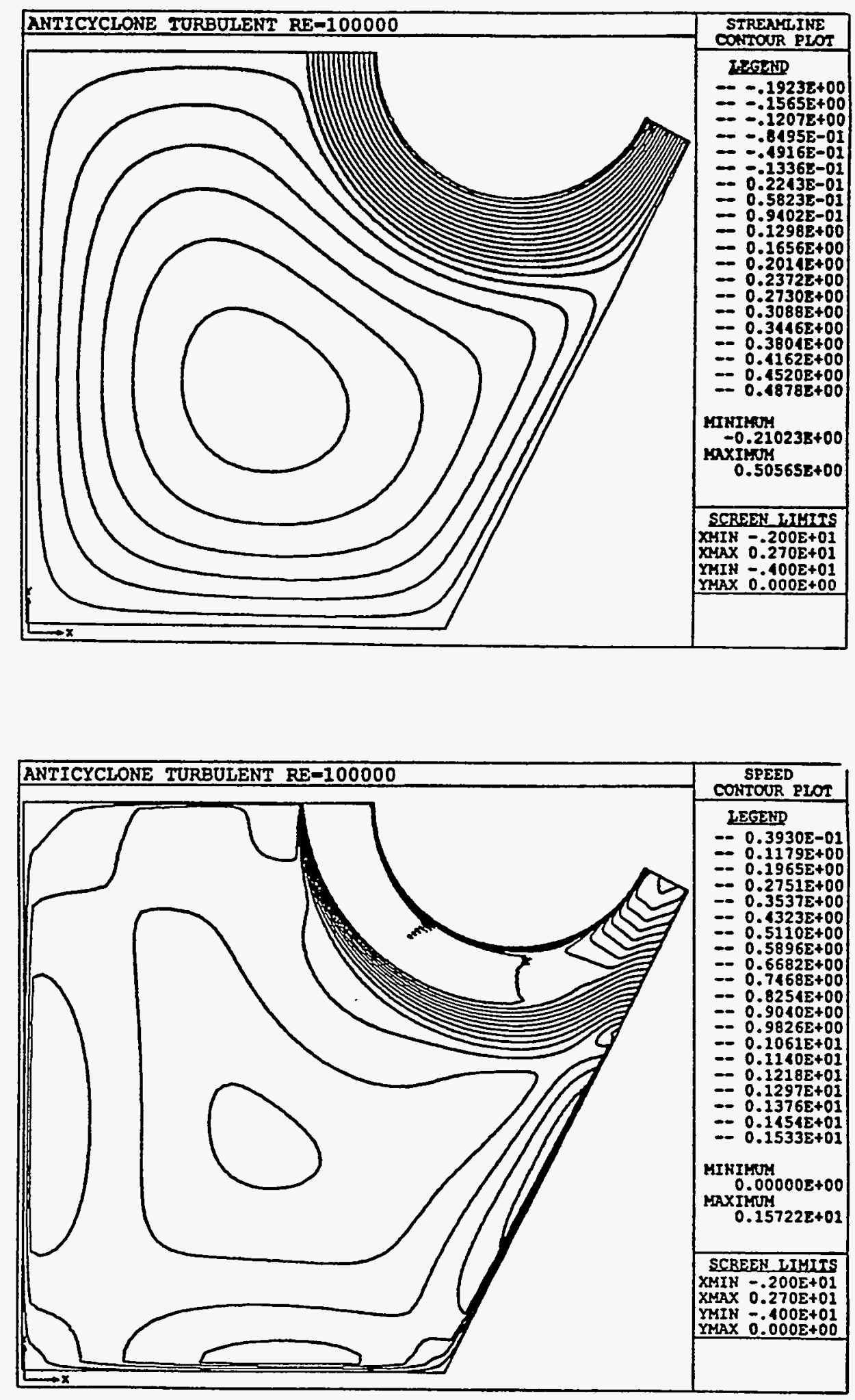

Figure 2.7. Streamlines (top) and speed contours (bottom) for $R e=10^{5}$ (turbulent). 

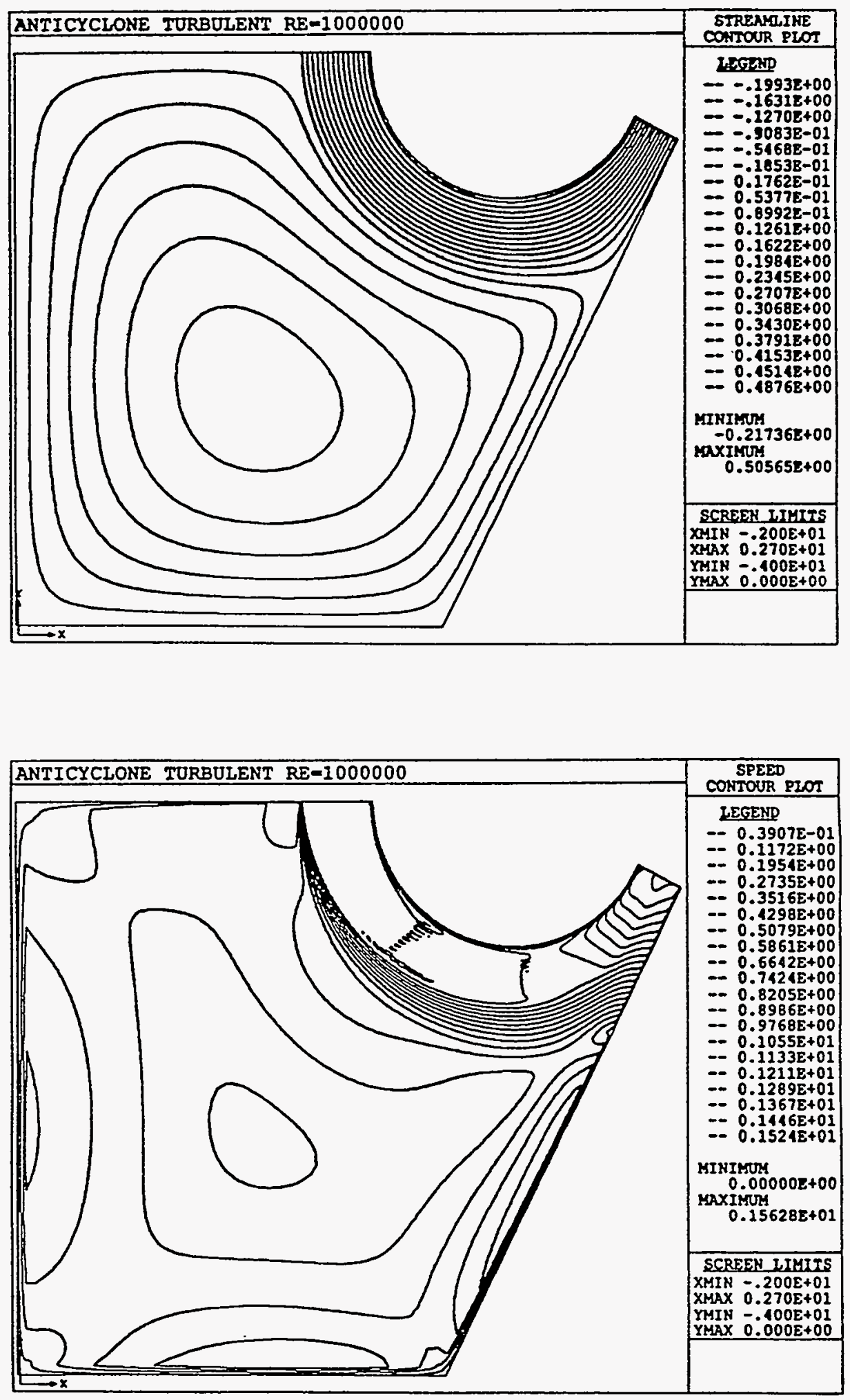

Figure 2.8. Streamlines (top) and speed contours (bottom) for $R e=10^{6}$ (turbulent). 

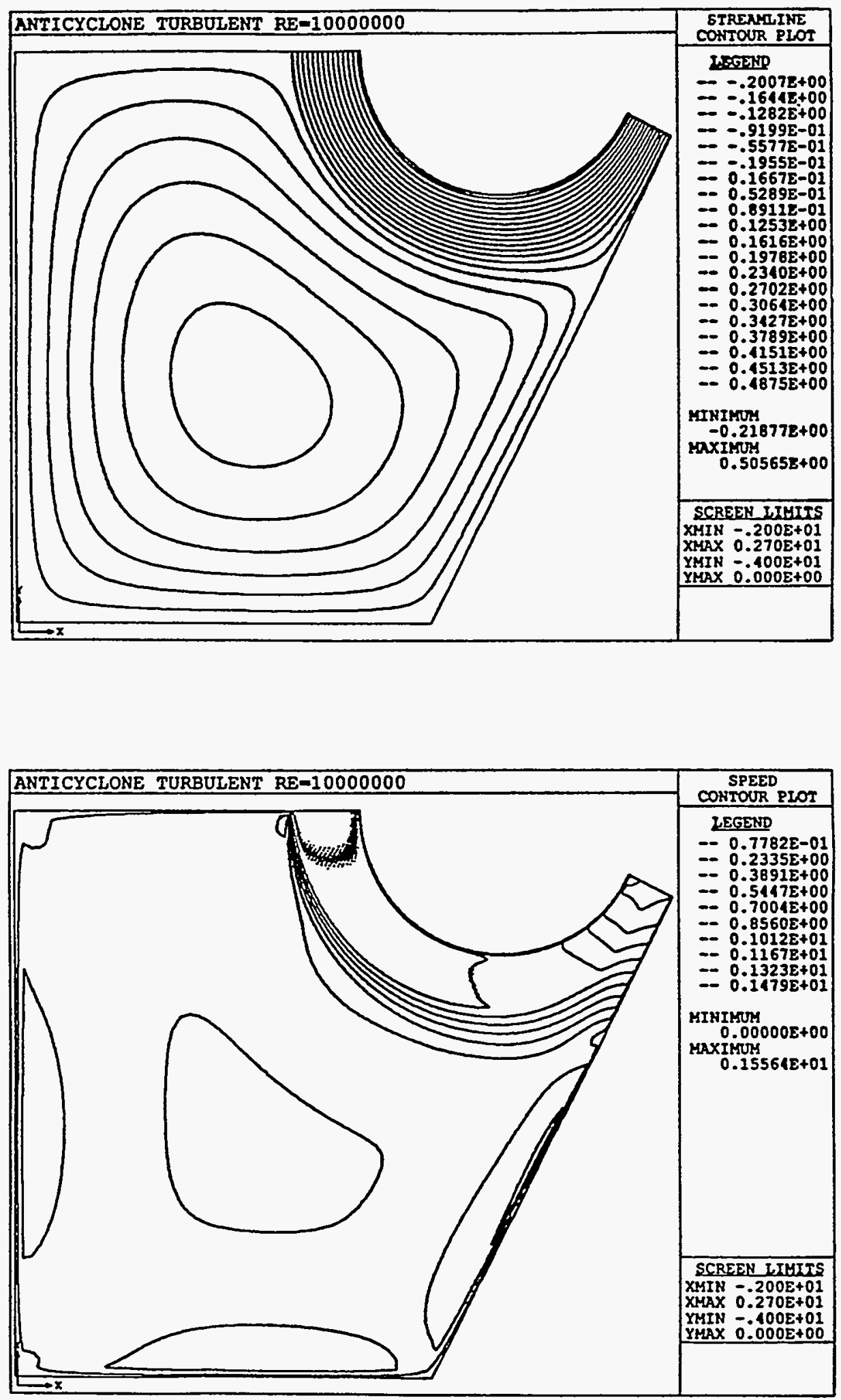

Figure 2.9. Streamlines (top) and speed contours (bottom) for $R e=10^{7}$ (turbulent). 


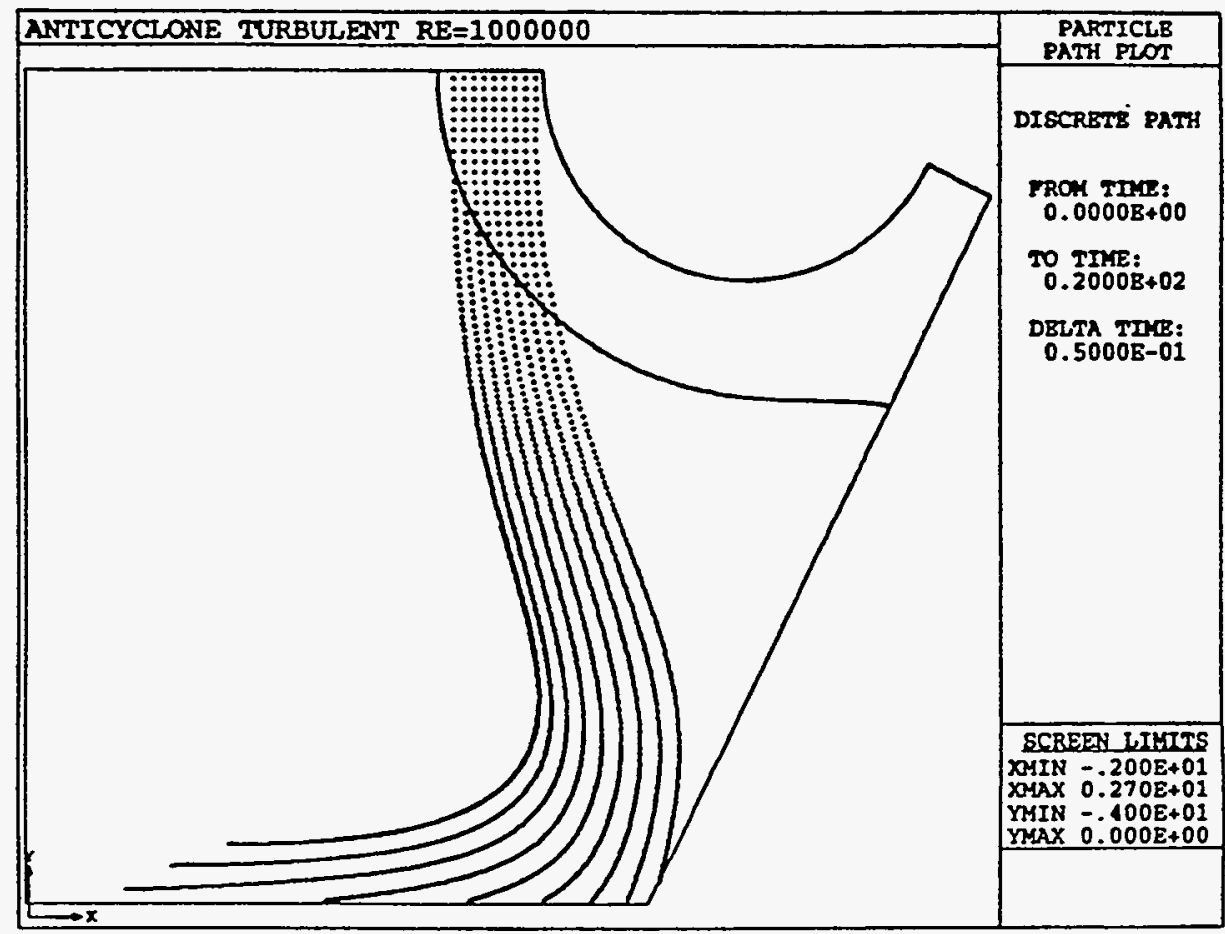

Figure 2.10. Particle motion for $R e=10^{6}$ (turbulent): $D_{p} / 2 H=1.0 \times 10^{-4}, \rho_{p} / \rho=1.2 \times 10^{4}$.

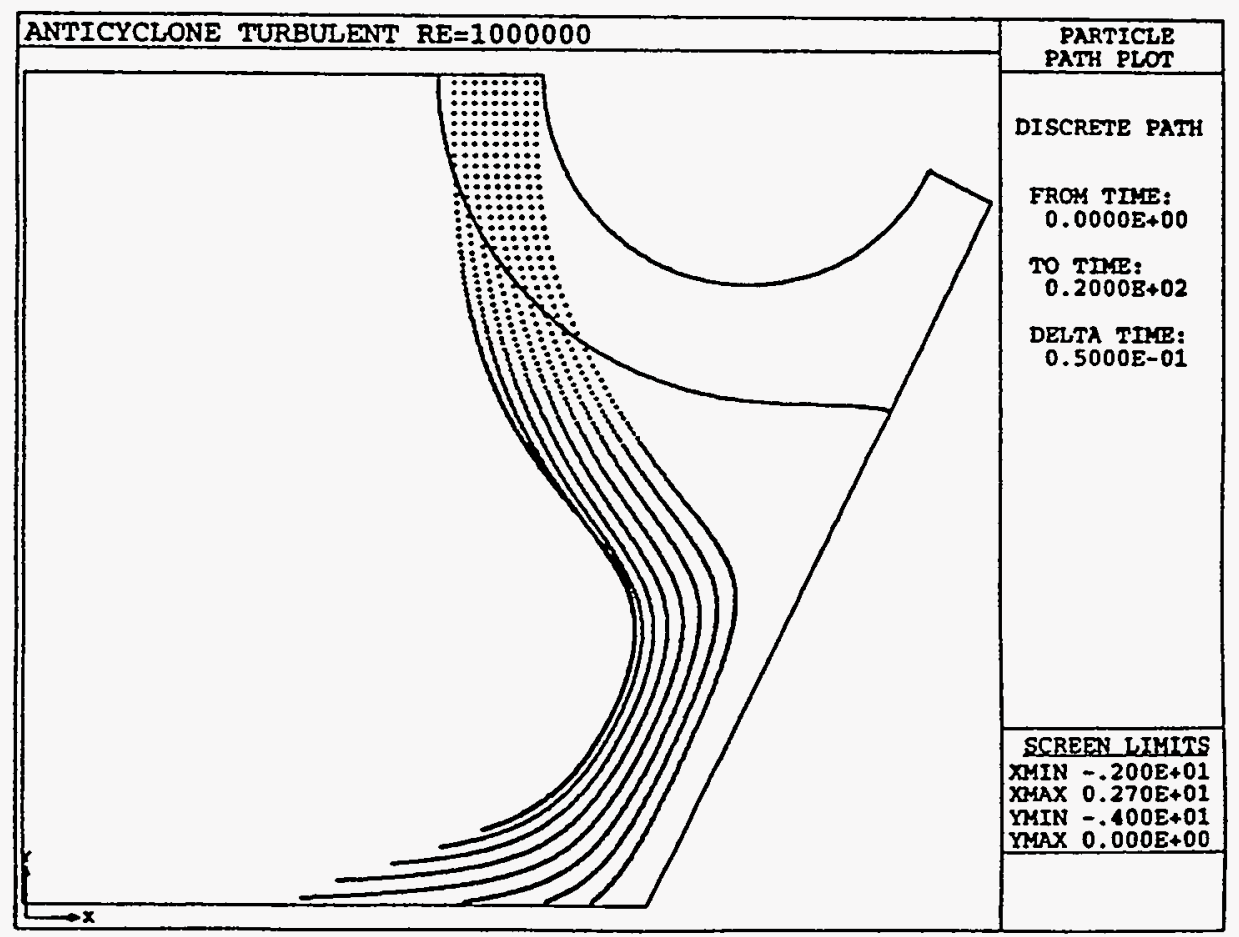

Figure 2.11. Particle motion for $R e=10^{6}$ (turbulent): $D_{p} / 2 H=1.0 \times 10^{-4}, \rho_{p} / \rho=0.6 \times 10^{4}$. 


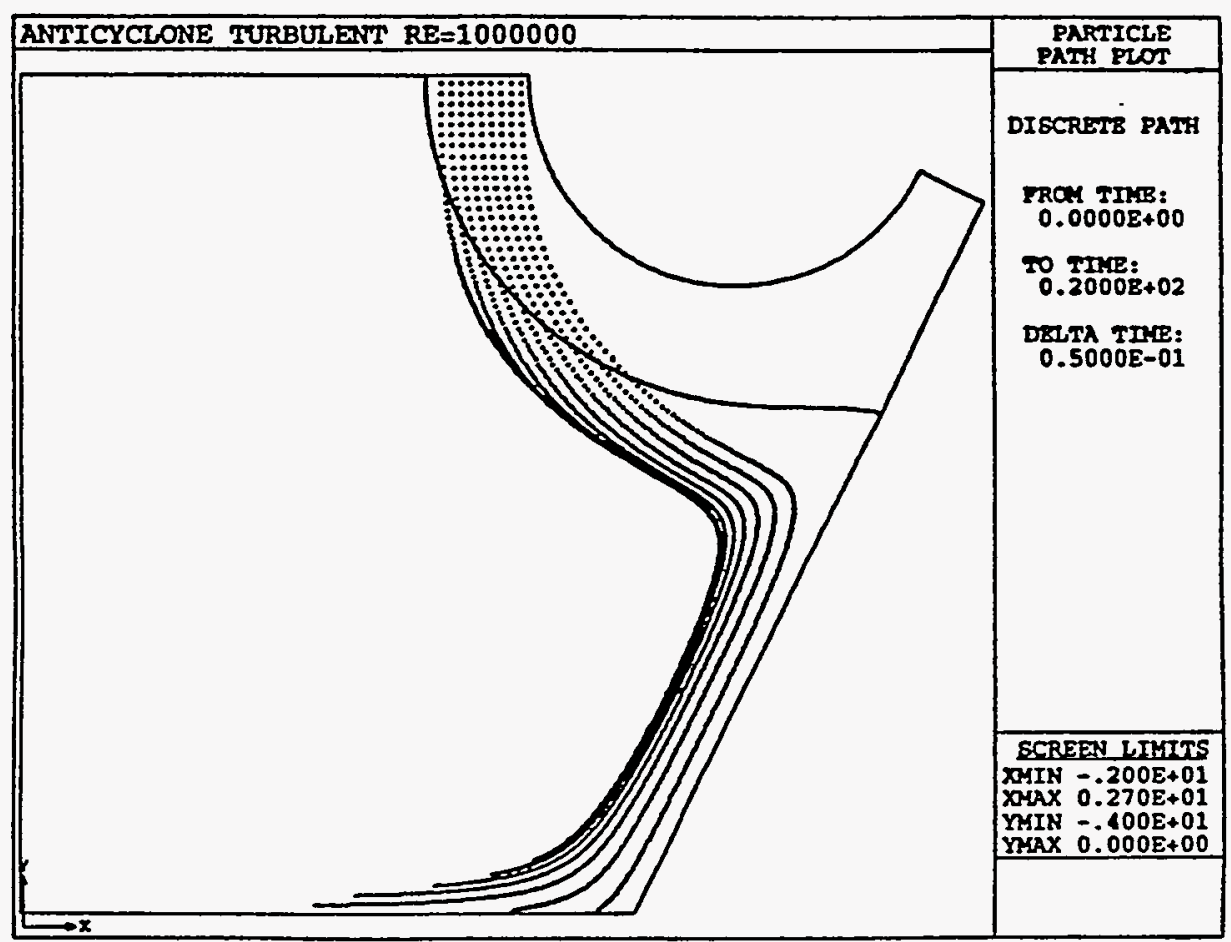

Figure 2.12. Particle motion for $R e=10^{6}$ (turbulent): $D_{p} / 2 H=1.0 \times 10^{-4}, \rho_{p} / \rho=0.3 \times 10^{4}$.

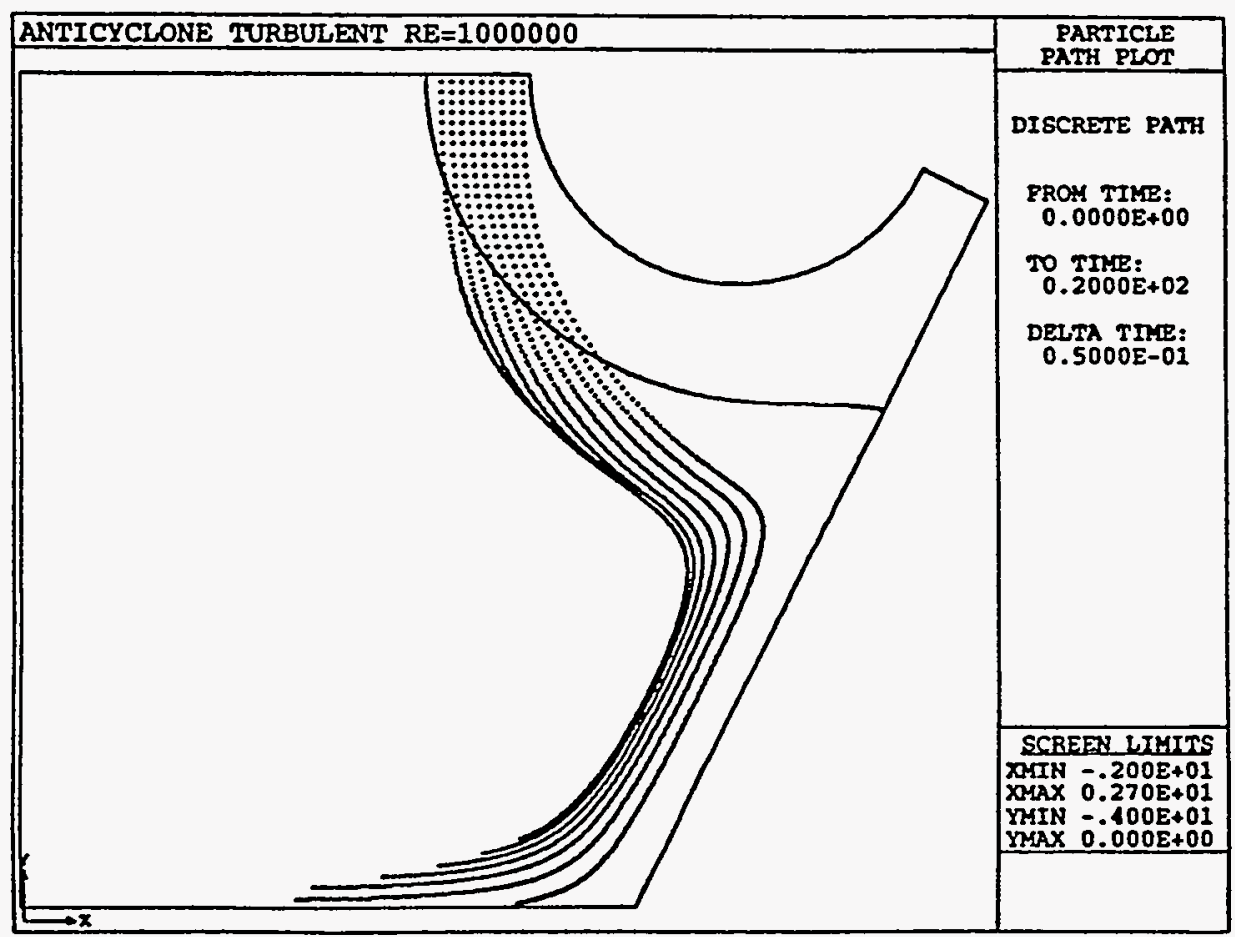

Figure 2.13. Particle motion for $R e=10^{6}$ (turbulent): $D_{p} / 2 H=0.5 \times 10^{-4}, \rho_{p} / \rho=1.2 \times 10^{4}$. 


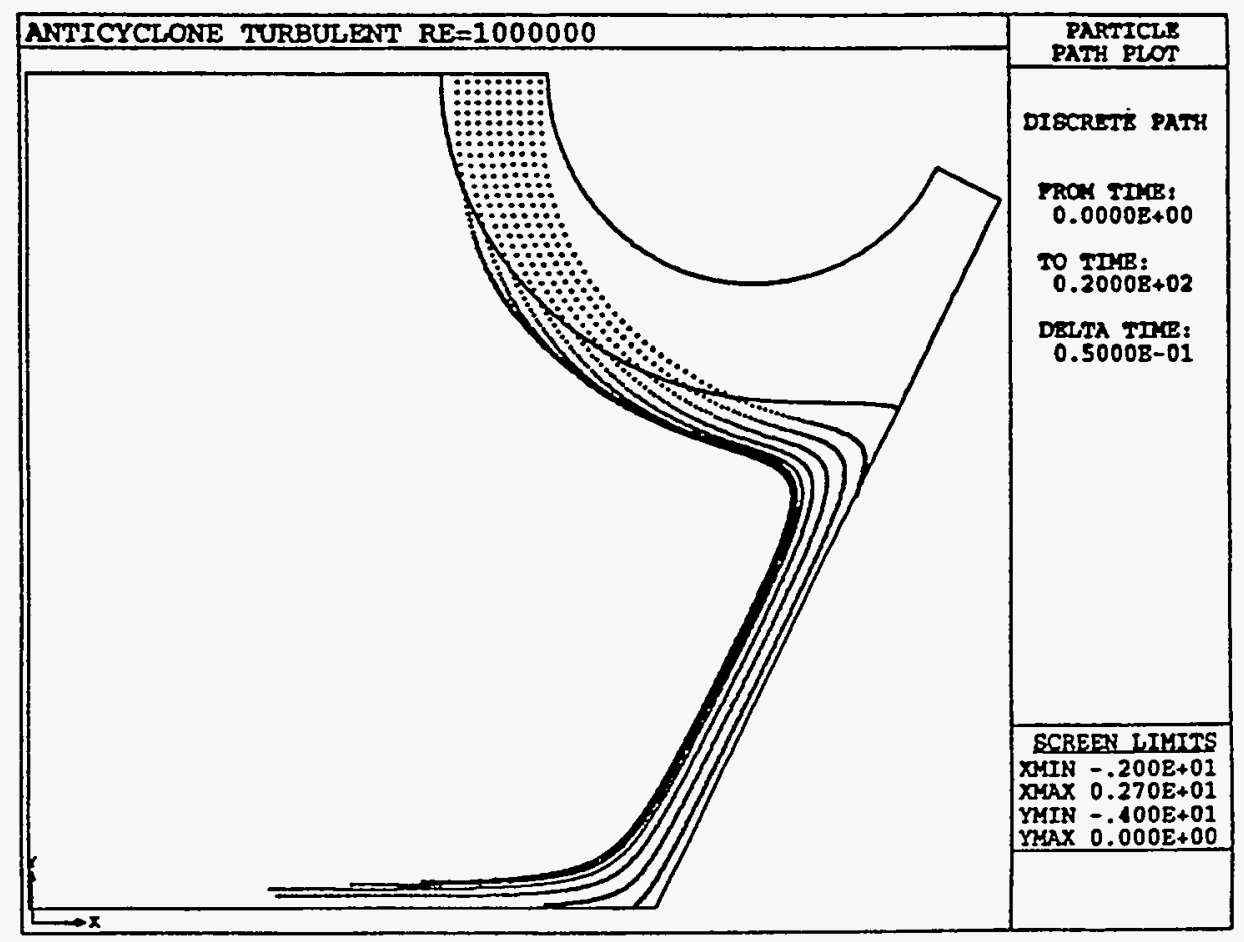

Figure 2.14. Particle motion for $R e=10^{6}$ (turbulent): $D_{p} / 2 H=0.5 \times 10^{-4}, \rho_{p} / \rho=0.6 \times 10^{4}$.

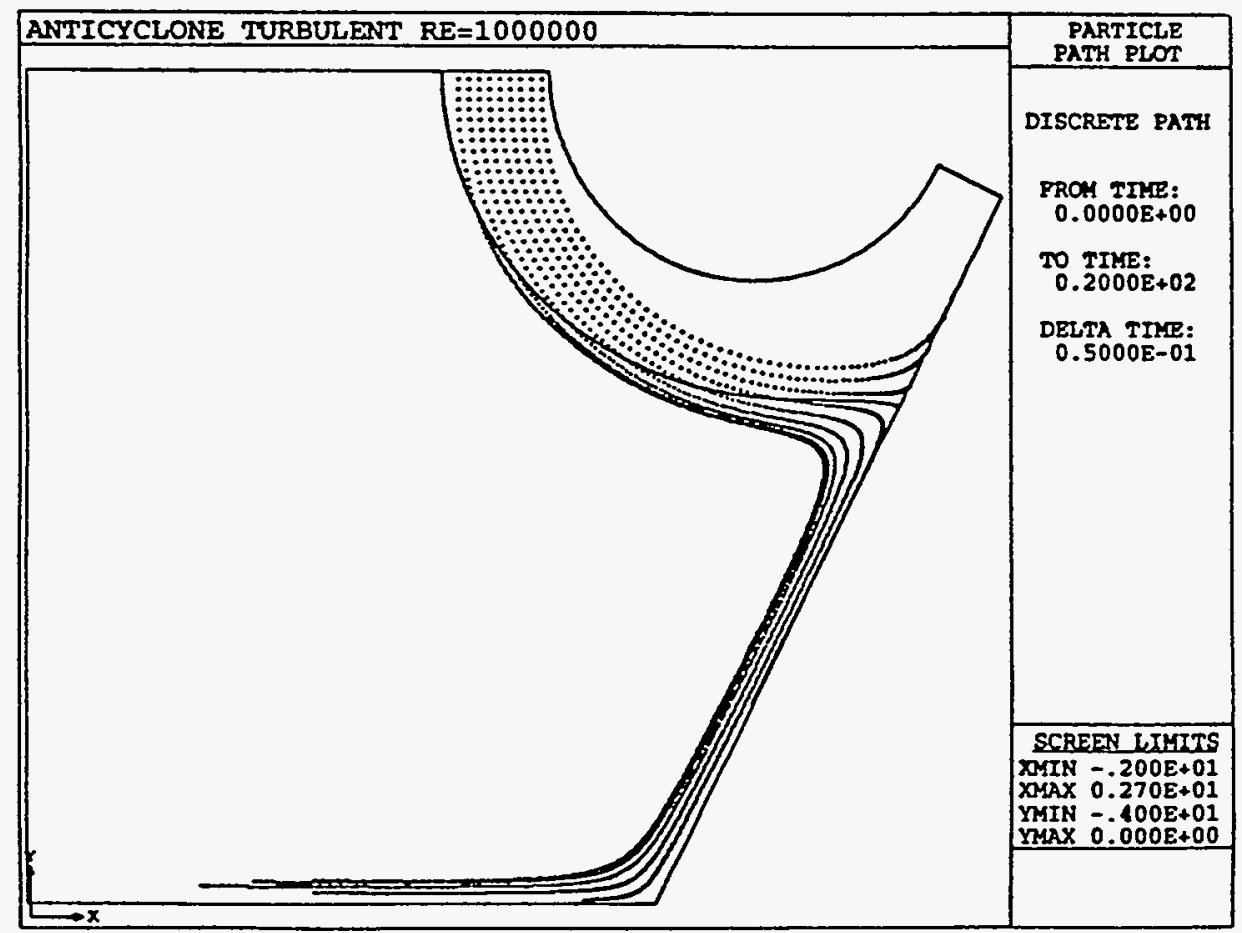

Figure 2.15. Particle motion for $R e=10^{6}$ (turbulent): $D_{p} / 2 H=0.5 \times 10^{-4}, \rho_{p} / \rho=0.3 \times 10^{4}$. 


\section{Approximate Analytical Analysis of Anticyclones}

In this section, a closed-form analytical expression is developed to predict the exit angle $\theta_{E}$, the angular position at which all particles have been transferred from the main flow to the recirculating flow. Each particle travels on a trajectory of the form $r=r(\theta)$, where this notation corresponds to a polar coordinate system with its radial origin at the wall's center of curvature and its angular origin at the inlet (see Figure 1.2). In the equations of motion, these trajectories are parameterized by the time $t: r=r(t), \theta=\theta(t)$. To specify a trajectory, it is necessary to prescribe the particle position and velocity at a given time. Here, it is assumed that at $t=0$ a particle enters the chamber via the inlet moving with the fluid velocity: $r=R_{0}, \dot{r}=0, \theta=0$, and $R_{0} \dot{\theta}=U$, where the dot denotes a time derivative, $R_{0}$ is the initial radial position of the particle, and $U$ is the fluid velocity at the inlet. Based on the fluid-flow simulation results presented in the previous section, the fluid is assumed to travel with constant speed around the curved wall, which yields the fluid velocity field $\vec{u}(r, \theta, t)=U \hat{e}_{\theta}(\theta)$. The dividing streamline is approximated as a circular curve of radius $R_{2}=R_{1}+H$, where $R_{1}$ is the radius of curvature of the curved wall and $H$ is the inlet width. The exit angle is defined by the following relations: $r(0)=R_{0}=R_{1}$ (the particle is initially adjacent to the curved wall) and $r\left(\theta_{E}\right)=R_{2}=R_{1}+H$ (the particle crosses the dividing streamline).

The equations of motion can be expressed in polar coordinates:

$$
\begin{gathered}
\ddot{r}-r \dot{\theta}^{2}=-\left(\frac{18 \mu}{\rho_{p} D_{p}^{2}}\right) \tilde{c}_{D} \dot{r}, \\
r \ddot{\theta}+2 \dot{r} \dot{\theta}=-\left(\frac{18 \mu}{\rho_{p} D_{p}^{2}}\right) \tilde{c}_{D}(r \dot{\theta}-U), \\
\tilde{c}_{D}=\tilde{c}_{D}\left[R e_{p}\right]=\tilde{c}_{D}\left[\frac{\rho D_{p}}{\mu} \sqrt{\dot{r}^{2}+(r \dot{\theta}-U)^{2}}\right],
\end{gathered}
$$

where the Turton-Levenspiel relation [3] for the normalized drag coefficient is used in Equation (3.3).

Considerable simplification of this coupled system of nonlinear ODEs is achieved by replacing Equation (3.2) with its large-drag limit, which satisfies the specified initial conditions:

$$
r \dot{\theta}=U .
$$

This analysis is not limited to the large-drag limit, however, since Equations (3.1) and (3.4) imply an approximate trajectory $r=R_{0} \exp \left(\theta^{2} / 2\right)$ in the zero-drag limit, which is close to the exact zero-drag trajectory $r=R_{0} / \cos \theta$ for angles up to about $45^{\circ}$.

Equations (3.1), (3.3), and (3.4) can be combined to eliminate the time $t$ in favor of the angle $\theta$. This yields the following equations, where $s$ is a quantity describing the particle trajectory with $s(0)=0$ required by the initial conditions:

$$
\begin{gathered}
\frac{d s}{d \theta}=1-\left(\frac{18 \mu r}{\rho_{p} D_{p}^{2} U}\right) \tilde{c}_{D}\left[\frac{\rho D_{p} U}{\mu} s\right] s, \\
s=\frac{1}{r} \frac{d r}{d \theta} .
\end{gathered}
$$


From Equation (3.5), it is seen that, as $\theta$ increases, $s$ rises from 0 with an initial slope of 1 to asymptotically approach a constant value $m$ given approximately by

$$
1=\left(\frac{9 \mu\left(R_{0}+R_{2}\right)}{\rho_{p} D_{p}^{2} U}\right) \tilde{c}_{D}\left[\frac{\rho D_{p} U}{\mu} m\right] m,
$$

where the $r$ variation in Equation (3.5) has been suppressed by replacing $r$ with the approximate constant value $\left(R_{0}+R_{2}\right) / 2$. This is a reasonable approximation so long as the inlet width $H$ is appreciably smaller than the wall radius of curvature $R_{1}$. An approximation to the solution of Equation (3.5) which possesses the above properties of the actual solution is

$$
s=\frac{1}{r} \frac{d r}{d \theta}=m \tanh (\theta / m)
$$

Equation (3.8) can be integrated in closed form to find an approximate particle trajectory:

$$
\frac{r}{R_{0}}=[\cosh (\theta / m)]^{m^{2}} \text {. }
$$

The exit angle $\theta_{E}$ is determined by selecting $R_{0}=R_{1}$ and $r=R_{2}$ in Equations (3.7) and (3.9):

$$
\begin{gathered}
1=\left(\frac{9 \mu\left(R_{1}+R_{2}\right)}{\rho_{p} D_{p}^{2} U}\right) \tilde{c}_{D}\left[\frac{\rho D_{p} U}{\mu} m_{E}\right] m_{E}, \\
\frac{R_{2}}{R_{1}}=\left[\cosh \left(\theta_{E} / m_{E}\right)\right]^{m_{E}^{2}} .
\end{gathered}
$$

Table 3.1 gives the $\theta_{E}$ values determined using Equations (3.10) and (3.11) for the particle-motion simulations presented in the previous section. In all cases, the agreement between the analytical results and the simulation results is seen to be very good.

Table 3.1. Comparison of analytical and simulation results for the exit angle.

\begin{tabular}{|c|c|c|c|c|c|c|}
\hline Figure & $D_{p} / 2 H$ & $\rho_{p} / \rho$ & $S t$ & $m_{E}$ & $\theta_{E}$ (analytical) & $\theta_{E}$ (simulation) \\
\hline \hline 2.10 & $1.0 \times 10^{-4}$ & $1.2 \times 10^{4}$ & 6.67 & 1.1051 & $54^{\circ}$ & $52^{\circ}$ \\
\hline 2.11 & $1.0 \times 10^{-4}$ & $0.6 \times 10^{4}$ & 3.33 & 0.6978 & $59^{\circ}$ & $58^{\circ}$ \\
\hline 2.12 & $1.0 \times 10^{-4}$ & $0.3 \times 10^{4}$ & 1.67 & 0.4349 & $71^{\circ}$ & $71^{\circ}$ \\
\hline 2.13 & $0.5 \times 10^{-4}$ & $1.2 \times 10^{4}$ & 1.67 & 0.5338 & $64^{\circ}$ & $65^{\circ}$ \\
\hline 2.14 & $0.5 \times 10^{-4}$ & $0.6 \times 10^{4}$ & 0.83 & 0.3216 & $85^{\circ}$ & $87^{\circ}$ \\
\hline 2.15 & $0.5 \times 10^{-4}$ & $0.3 \times 10^{4}$ & 0.42 & 0.1896 & $130^{\circ}$ & not achieved \\
\hline
\end{tabular}




\section{Conclusions and Future Efforts}

A method of particle separation has been examined in which particle separation from a flow stream is achieved by transferring particles across a streamline dividing two distinct flow streams rather than by impacting particles onto a solid surface. Termed nonimpact particle separation, this approach has many desirable features, particularly that surface contamination, particle modification, and surface modification are all virtually eliminated. The anticyclone, one device employing nonimpact particle separation, uses a wall curving away from the main particle-laden flow stream to redirect the main flow, which causes the particles to be transferred to the adjacent recirculating flow driven by the main flow. Numerical simulations indicate that an anticyclone performs as desired for wide ranges of flow and particle parameters. Moreover, a closed-form analytical expression for particle motion in an anticyclone is developed and is found to be in good agreement with the simulation results.

Several uncertainties remain, however, that should be the focus of future investigations. First, the effect of turbulence on various characteristics of nonimpact particle separation needs to be better quantified. The accuracy of the $k-\varepsilon$ turbulence model employed in the simulations is uncertain, particularly in the complex geometry examined here. The effect of turbulent fluctuations on particle motion is also difficult to quantify. Second, the effect of particle volume fraction on nonimpact particle separation needs to be examined further. In the simulations and analysis here, particle volume fraction and mass fraction are assumed to be very small. Therefore, particles are treated as isolated and noninteracting, and particle motion does not couple back and influence the flow. It is not difficult to envision operating conditions for which it would be desirable to relax these constraints. Third, the force of the fluid on the particles is represented in a particularly simple form and probably needs to be refined. For example, virtual-mass and Basset-history effects are neglected. Fourth, the effects of flow unsteadiness on nonimpact particle separation need to be better clarified. Flow unsteadiness can include gradual drifts in operating conditions, abrupt changes such as startup and shutdown, and inherent phenomena such as turbulent large-scale structures or flow instabilities. Fifth, the circumstances for which flow three-dimensionality may become significant and affect nonimpact particle separation need to be better understood. All simulations here have assumed that a twodimensional representation is adequate, at least for preliminary analyses.

In order to develop useful devices employing nonimpact particle separation, the above phenomena need to be understood in a quantitative fashion. Further simulations and corresponding experiments are required to develop this understanding. Of additional interest is the investigation of alternative geometries, particularly axisymmetric configurations employing nonimpact particle separation. 


\section{References}

[1] Fluid Dynamics International, FIDAP Users Manual, version 7.0 (Fluid Dynamics International, Evanston, IL, 1993).

[2] R. Clift, J. R. Grace, and M. E. Weber, Bubbles, Drops, and Particles (Academic Press, New York, 1978), pp. 286-288.

[3] R. Turton and O. Levenspiel, “A Short Note on the Drag Correlation for Spheres," Powder Technology 47, 83-86 (1986). 


\section{Distribution}

\begin{tabular}{|c|c|c|c|}
\hline MS 0749 & 6203 & A. $\mathrm{P}$. & Sylwester \\
\hline MS 0709 & 6212 & H. P. & Stephens \\
\hline MS 0709 & 6212 & N. B. & Jackson \\
\hline MS 1137 & 6402 & M. D. & Allen \\
\hline MS 0756 & 6610 & G. C. & Allen \\
\hline MS 0755 & 6612 & W. & Einfeld \\
\hline MS 0755 & 6612 & B. D. & Zak \\
\hline MS 9042 & 8345 & C. $\mathrm{M}$. & Hartwig \\
\hline MS 9042 & 8345 & S. $\mathbf{K}$. & Griffiths \\
\hline MS 9052 & 8361 & D. $R$. & Hardesty \\
\hline MS 0841 & 9100 & P. J. & Hommert \\
\hline MS 0828 & 9102 & R. D. & Skocypec \\
\hline MS 0833 & 9103 & J. $\mathrm{H}$. & Biffle \\
\hline MS 0828 & 9104 & E. D. & Gorham \\
\hline MS 0826 & 9111 & W. & Hermina \\
\hline MS 0826 & 9111 & C. E. & Hickox \\
\hline MS 0826 & 9111 & T. J. & O'Hern \\
\hline MS 0834 & 9112 & A. C. & Ratzel \\
\hline MS 0834 & 9112 & F. & Gelbard \\
\hline MS 0834 & 9112 & J. $R$. & Torczynski (10) \\
\hline MS 0835 & 9113 & T. C. & Bickel \\
\hline MS 0835 & 9113 & D. R. & Adkins \\
\hline MS 0827 & 9114 & R. T. & McGrath \\
\hline MS 0827 & 9114 & J. E. & Brockmann \\
\hline MS 0827 & 9114 & A. $\mathbf{S}$. & Geller \\
\hline MS 0827 & 9114 & D. J. & Rader (10) \\
\hline MS 0825 & 9115 & W. H. & Rutledge \\
\hline MS 0836 & 9116 & C. W. & Peterson \\
\hline MS 0443 & 9117 & H. S. & Morgan \\
\hline MS 0437 & 9118 & $\mathrm{E}$. & Chen, actg. \\
\hline MS 1007 & 9672 & L. R. & Shipers \\
\hline
\end{tabular}

MS $9018 \quad 8523-2$ Central Technical Files (1)

MS 08994414 Technical Library (5)

MS 061912615 Print Media (i)

MS 0100 7613-2 Document Processing for DOE/OSTI (2)

Yung Sung Cheng

Inhalation Toxicology Research Institute

P. O. Box 5890

Albuquerque, NM 87185-5890

Clyde Frank

U.S. Department of Energy

Forrestal Building, EM-50, 6B-158

1000 Independence Avenue

Washington, DC 20585

Mark D. Hoover

Inhalation Toxicology Research Institute

P. O. Box 5890

Albuquerque, NM 87185-5890

David Leith

University of North Carolina

C.B. 7400, Rosenau Hall

Chapel Hill, NC 27599-7400

Dale A. Lundgren

University of Florida

Department of Environmental Engineering

410 Black Hall

Gainesville, FL 32611

Virgil A. Marple

University of Minnesota

111 Church St. SE

Minneapolis, MN 55455

George Newton

Inhalation Toxicology Research Institute

P. O. Box 5890

Albuquerque, NM 87185-5890

Heidi D. Oas

Air Quality Engineering, Inc.

3340 Winpark Drive

Minneapolis, MN 55427-2083

Hsu-Chi Yeh

Inhalation Toxicology Research Institute

P. O. Box 5890

Albuquerque, NM 87185-5890 



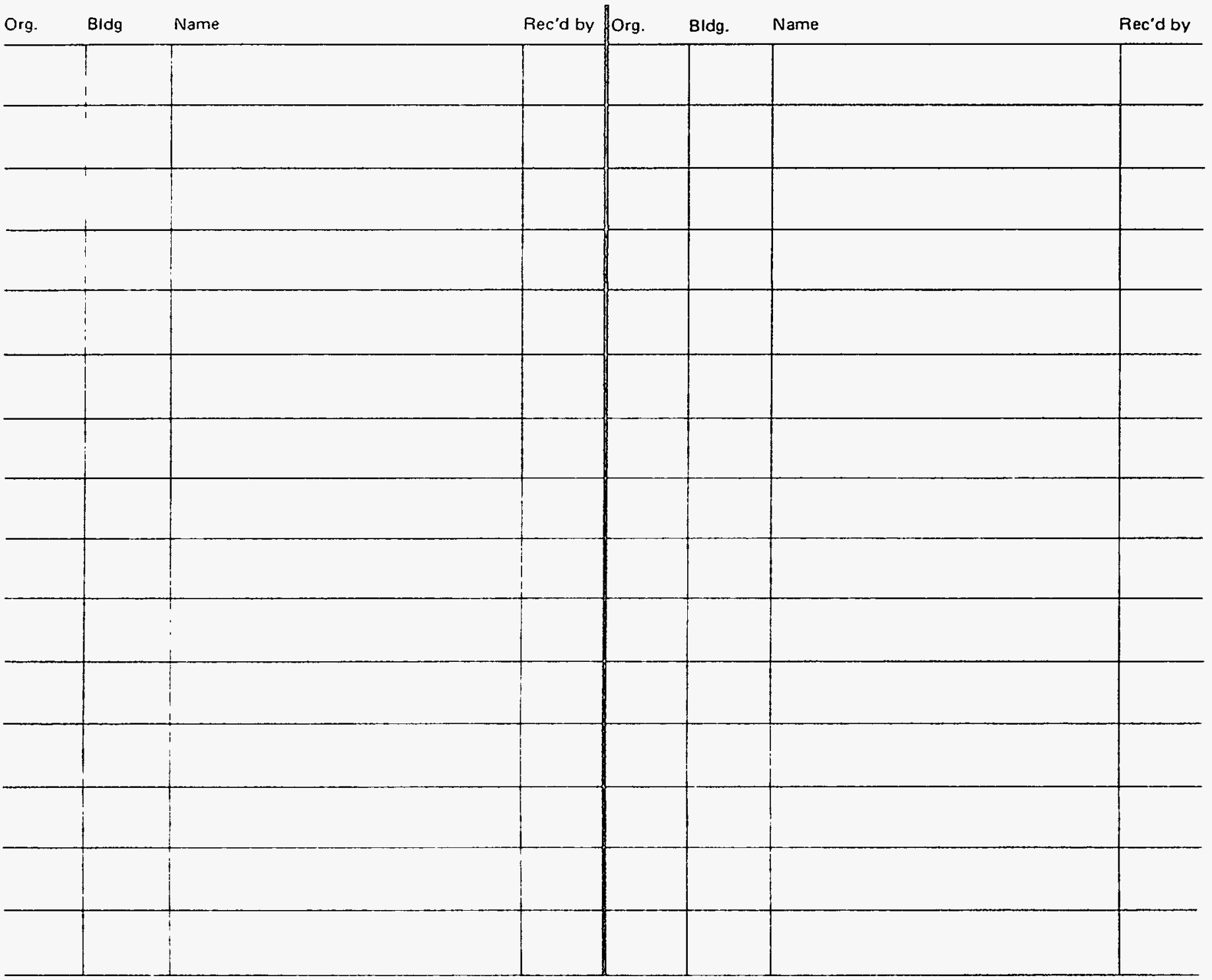

(กص) Sandia National Laboratiories 